\title{
Uluslararası Taşımacılık İşletmelerinin Çekici Araç Seçimlerinin EntegreAHP, Entropi ve TOPSIS Yöntemleri Kullanılarak Analizi
}

\section{Evaluation of Decision Alternatives of International Transportation Companies Concerning Urban Transportation Using Integrated AHP, Entropy and TOPSIS Methods}

\author{
Dr. Öğr. Üyesi Ömer Faruk GÖRÇÜN (iD) 1
}

\begin{abstract}
$\ddot{\mathbf{O} z}$
Uluslararası taşımacılık işletmelerinin doğru araç seçimi operasyonel verimlilik ve etkinlik açısından son derece önemli bir konudur. Taşımacılık faaliyetlerinin etkinliği uygun araç ve ekipman seçimine büyük ölçüde bağımlılık göstermektedir. Öte yandan araç seçimi karar alıcıların sezgileri ve kişisel yargıları ile yapılamayacak kadar çok sayıda faktör tarafından etkilenen bir süreçtir. Bu nedenle bir lojistik İşletmenin çekici araç seçimine ilişkin süreci çok kriterli karar verme yöntemleri kullanarak sistematik ve yapısal bir perspektifte değerlendirmesi en iyi ve uygun aracın seçimine olanak sağlayabilir. Bu kapsamda lojistik işletmelerin karayolu taşıma faaliyetlerinde kullanacaklar çekici araçların seçiminde kullanılmak üzere entegre Analitik Hiyerarşi Prosesi (AHP), Entropi ve TOPSIS yöntemlerinden oluşan hibrid bir model önerilmektedir. Önerilen bu model kullanılarak elde edilen sonuçların konu ile ilgili olarak akademik alanda çalışanların yanı sıra, lojistik işletmeler ile lojistik süreçlerde yer alan diğer aktörler tarafindan da kullanılabilir nitelikte olacağı öngörülmektedir.
\end{abstract}

Anahtar Kelimeler: AHP, entropi, TOPSIS, taşımacılık yönetimi, çekici araç seçimi, lojistik

Makale Türü: Araştırma

\begin{abstract}
Proper heavy vehicle selection is an extremely important issue for international freight transportation companies in an aspect of operational efficiency and performance. Effectivity of transportation activities depends on proper vehicle and equipment selection mostly. In addition to that, heavy vehicle selection is a process, which was affected by many factors and it is not possible to succeed depending on only personal judgments and intuitional approaches of decision-makers. Therefore, in a systematic and structural perspective, evaluation of heavy vehicle selection process by using the multi-criteria decisionmaking methodologies can provide an opportunity for selection of proper and the best heavy vehicle. Within this scope, a hybrid multi-criteria decision-making model, which integrated the AHP, Entropy, and TOPSIS method is proposed in order to use in the selection process of the heavy vehicle, which is used in the international freight transportation activities by logistics companies. It İs foreseen that the obtained results by using the selected model can be useful for logistics companies, other parties of logistics processes as well as researchers who work İn the academic field.
\end{abstract}

Keywords: Entropy, TOPSIS, transportation management, selection of heavy vehicle, logistics

Paper Type: Research

${ }^{1}$ Kadir Has Üniversitesi, Uygulamalı Bilimler Fakültesi, omer.gorcun@khas.edu.tr.

Atıf için (to cite): Görçün, Ö. F. (2019). Uluslararası Taşımacılık İşletmelerinin Çekici Araç Seçimlerinin EntegreAHP, Entropi ve TOPSIS Yöntemleri Kullanılarak Analizi. Afyon Kocatepe Üniversitesi Sosyal Bilimler Dergisi, 21(3), 899-922. 


\section{Giriş}

Taşımacılık faaliyetleri lojistik süreçlerin en önemli bileşenlerinden birisidir. Aynı zamanda tedarik zinciri içerisinde yer alan tedarikçiler, üreticiler, perakendeciler ve tüketiciler gibi aktörler arasında söz konusu olabilecek konumlanma problemini çözebilmeye olanak sağlayabilen en temel enstrüman konumundadır. Dolayısıyla taşımacılık bu aktörlerin birbirlerinden farklı noktalarda konumlanmış olmalarına bağlı olarak gereksinimlerine erişebilmelerini mümkün kılabilmektedir. Gerçekte taşımacılık faaliyeti olmaksızın tedarik zinciri içerisinde gerçekleşen hammadde, yarı mamul ve ürün akışlarının gerçekleşmesi olanaklı görünmemektedir. Dolayısıyla taşımacılık bir lojistik süreçte vazgeçilmesi en azından günümüz koşulları ile mümkün olmayan lojistik bir aktivitedir.

Oynadığı son derece önemli role karşılık taşımacılık faaliyetleri bir tedarik zincirinde en yüksek kaynak kullanımına ve maliyete neden olan bir aktivite olma durumundadır. Buna karşıllk taşıma faaliyetleri üretim vb. süreçler gibi ürüne ilişkin katma değer yaratan bir niteliğe de sahip değildir. Hammadde ve ürünler taşındıkları için katma değer elde etmemekte, herhangi bir dönüștürücü ișlem olmasa da varıș noktasında materyale ilișkin gereksinimler ürünün katma değerini belirlemektedir. $\mathrm{Bu}$ yönü ile daha efektif bir alternatif söz konusu olduğunda taşımacılık faaliyetleri bir tedarik zincirinde en çabuk vazgeçilecek lojistik faaliyetlerin başında gelmektedir. Bunun doğal bir sonucu olarak, tümüyle vazgeçilmese bile, mümkün olduğunda çok hızlı bir biçimde dönüşüm gösterebilmekte, farklı taşıma türleri, sistemleri ve alternatifleri çok çabuk bir biçimde sisteme entegre edilebilmektedir.

Genel bir perspektifte değerlendirildiğinde bir taşıma sisteminin tercih edilebilirliğinin en temel göstergelerinin başında kullanıcılara yaratacağı maliyetlerin yanı sıra, elde edilecek faydanın düzeyi gelmektedir. Dolayısıyla bir taşıma operasyonunda kullanılan kaynak düzeyi mümkün olabilen en düşük, elde edilecek fayda düzeyi yine mümkün olabilecek en yüksek şekilde elde edildiğinde taşıma faaliyetlerini organize eden aktörün yanı sıra sistemde yer alan aktörlerin verimlilikleri ve performansı önemli ölçüde artış göstermektedir. Bunun sonucunda taşımacılık işletmesinin tedarik zinciri içerisindeki yeri sağlamlaşırken, tercih edilebilirliği artış göstermektedir.

$\mathrm{Bu}$ perspektifte taşımacılık işletmesinin sahip olduğu taşıma unsurları işletmenin performansını ve etkinliğini doğrudan etkilerken, beraberinde hizmet verdiği tedarik zincirinin de performansına da dolaylı olarak etki edebilmektedir. Bu nedenle taşıma işletmesinin sahip olduğu ekipman ve araçların gereksinimlere en uygun biçimde cevap verebilir nitelikte olması gerekmektedir. Dolayısıyla taşıma işletmelerin araç parklarını oluştururken oldukça titiz bir yaklaşım göstermeleri ve operasyonlarında kullanacakları araçları seçerken gereksinimlerini dikkate almaları son derece önem arz eden konuların başında gelmektedir. Aynı zamanda taşıma operasyonlarında kullanacakları araçların seçimi ile ilgili süreç çok sayıda değişken ve faktör tarafından büyük ölçüde etkilendiği için karar alıcıların sezgisel yaklaşımları ve tecrübelerine dayanarak karar almaları en uygun taşıma araçlarının seçimi için yeterli olmayabilmektedir.

Bu kapsamda karar alıcıların araç seçimi ile ilgili kararlarını daha rasyonel ve nesnel bir ölçeğe dayandırabilmesi ve tercih edecekleri araçların bu perspektifte kendileri ve gereksinimleri açısından en uygun ve en iyi araçlar olabilmesi için sistematik ve yapısal bir çözüm yolu ortaya koyabilecek bir metodolojiye gereksinim duyulmaktadır. Bu açıdan değerlendirildiğinde, karayolu taşımacılı̆̆ türünde hizmet üreten işletmelerin karar alıcılarının kolay bir şekilde uygulayabilecekleri, aynı zamanda rasyonel ve gerçekçi kararların alınmasına olanak sağlayabilecek nitelikte çok kriterli karar verme metodolojilerinin kullanılması en uygun karayolu taşıma aracının seçimi için zorunluluk olarak görülmektedir. $\mathrm{Bu}$ gereksinim çerçevesinde en uygun aracın seçilebilmesi için AHP, Entropi ve TOPSIS yöntemlerinin entegre edildiği hibrid bir model önerilmektedir. Yöntem toplamda on dört adımdan oluşmaktadır. İlk dört adımda AHP yönteminin adımları kullanılarak karar süreçlerine etki eden ve sayısal olmayan faktörlerin önem dereceleri ve ağılıkları hesaplanmış, ikinci dört adımda ise entropi 
yönteminin adımları kullanılarak, AHP yöntemi ile elde edilenler dahil tüm faktörlerin ağırlıkları belirlenmiştir. Nihai olarak TOPSIS yöntemi kullanılarak, değerlendirmeye alınan karar alternatifleri için göreli önem değerleri hesaplanarak, söz konusu faktörler önem değerlerine göre sıralandırılmıştır.

Seçilen hibrid modelde AHP yönteminin yer almasının temel nedeni belirlenen bazı seçim kriterlerinin sayısal değerlere sahip olmaması ve karar alıcıların sözel ve kişisel yargılarına dayanıyor olmasıdır. Bu faktörlerin ölçülebilir değerlere dönüştürülebilmesi için AHP yöntemi önemli bir enstrüman olarak değerlendirilmiştir. Öte yandan sayısal değerlere sahip olan faktörlerin sayısı sayısal değerlere sahip olmayan faktörlere göre son derece fazladır. $\mathrm{Bu}$ faktörlerin tamamının AHP ile değerlendirilmesi karar alıcıları kişisel yargılarının sürece büyük ölçüde etki etmesine ve birtakım sapmaların meydana gelebilme riskine karşıllk entropi yöntemi ile bütün seçim kriterlerinin ağırlıkları hesaplanmıştır. Entropi yönteminin karar alıcıların kişisel yargı ve tutumlarını sürece dahil etmediği için AHP, SWARA ve Delphi tekniklerine göre daha rasyonel ve nesnel sonuçlar verebilmesi tercih edilmesinde öncelikli bir kriter olmuştur. TOPSIS metodunun seçilmesinin temel nedenlerinin başında uygulanmasının ve elde edilen sonuçların yorumlanmasının son derece kolay olması, ek olarak uygulanması ile ilgili olarak herhangi bir yazılım ve programa gereksinim duymamasıdır.

$\mathrm{Bu}$ çalışma ile elde edilen sonuçların daha rasyonel ve uygulanabilir olabilmesi için araştırma sürecinin başında uzmanlar kurulu olarak adlandırılan bir çalışma grubu oluşturulmuştur. Uzmanlar kurulu toplamda yedi kişiden oluşurken, üyeleri sektörde en az on beş yıl üst düzey yönetici ya da şirket sahibi olarak görev yapmış, aynı zamanda şirketlerinin karar alma süreçlerinde yer alan profesyoneller arasından seçilmiştir.

Araştırma süreci boyunca kurul üyeleri ile çok sayıda toplantı gerçekleştirilmiş, toplantılarda karar alma sürecine etki eden faktörler ile değerlendirmeye alınacak karar alternatifleri belirlenmiştir. Söz konusu faktörler belirlenirken her üye serbest bir biçimde görüşlerini dile getirmiş, öne sürülen görüşler araştırmayı yürütenler tarafindan kaydedilmiştir. Nihai olarak kurul üyelerinin ortak konsensüsü ile seçim kriterleri, karar alternatifleri ile birlikte, bu faktörler 1şığında hazırlanacak anketlerin yöneltilecekleri karar alıcıların özellikleri saptanmıştır.

Bu çalışma toplamda beş bölümden oluşmaktadır. Birinci bölümde konu genel çerçevesi ile birlikte değerlendirilirken, ikinci bölümde literatür taraması gerçekleştirilmiş, üçüncü bölümde kullanılan model materyal ve metot kısmında açılanarak, uygulama süreci detaylandırılmıştır. Dördüncü bölümde seçilen hibrid modelin kullanıldığı sayısal bir analiz gerçekleştirilirken, beşinci ve son bölümde ise elde edilen sonuçlar değerlendirilmiştir.

$\mathrm{Bu}$ çalışmanın literatürde görülen eksikliği gidermeye yönelik önemli katkılar sağlamasının yanı sıra, araştırma ile elde edilen sonuçlardan sadece akademik dünyada yer alan araştırmacıların değil, aynı zamanda lojistik işletmelerin yanı sıra, tedarik zincirlerinin diğer aktörlerin, taşımacılık işletmelerinin, çekici araç üreten işletmeler ile bu araçların finansmanı ile ilgili sürece dahil olan bankalar gibi finansal kuruluşların da faydalanması beklenmektedir. Çekici araç üreten işletmeler üretecekleri modelleri ve üretim süreçlerini elde edilen sonuçlara bağlı olarak gözden geçirebilecekleri gibi, finansman kuruluşları verecekleri kararların rasyonel olup olmadığına yönelik olarak bu çalışmada önerilen modeli değerlendirme süreçlerinde kullanabileceklerdir.

\section{Literatür Taraması}

$\mathrm{Bu}$ çalışmada önerilen çok kriterli karar verme modeline benzer bir biçimde AHP, Entropi ve TOPSIS yöntemleri kullanılarak yapılan çalışmalardan birisi Freeman ve Chen (2015) tarafından gerçekleştirilen yeşil tedarikçi seçimine ilişkin çalışmadır. Buna ek olarak Jozi, Shafiee, ve MoradiMajd (2012) entropi ve TOPSIS yöntemleri entegre olarak kullanarak çevresel risk değerlendirme ile ilgili bir çalışma gerçekleştirmişler, aynı yöntem çerçevesinde 
Chen, Wang ve Deng (2015) karayolu risk değerlendirmesi, Zhao, Wang ve Niu (2004) elektrik piyasasının değerlendirilmesi, Pan, Yi ve Li-Ting (2010) iletim hatlarının planlanması, Bo (2010) iletim projelerinde dış çevrenin değerlendirilmesi, Nıe ve Dong (2010) liman kentlerinde kurvaziyer turizmin rekabet edebilirliği, Ouyang, Chen ve Yang (2014) kalitenin ölçülmesi ve standartların sıralanması, Zhang, $\mathrm{Gu}, \mathrm{Gu}$ ve Zhang turizm destinasyon rekabet gücünün değerlendirilmesi, Wang ve Shao (2010) kömür madenlerinin güvenlik değerlendirilmesi, Cheng, Ren, Cu1 ve Tang (2012) bölgesel kalkınma modelleri, Deepa ve Swamynathan (2015) Mobil ad hoc ağları için kümeleme protokollerinin değerlendirilmesi, Wang, Tang ve Yan (2011) termik santrallerin yer seçimi, Zhang, Zhu ve Feng (2013) ile Lei, Robin ve Liu (2016) bölgesel arazi kullanım performansının değerlendirilmesi türünde çalışmalarda entropi ve TOPSIS yöntemleri entegre olarak kullanılmıştır.

Bunlara ek olarak, Hsu ve Hsu (2008) temel sağlık kuruluşlarında dış kaynak kullanma uygulamalarını analiz ederken, Zhao ve Guo (2014) Sürdürülebilirlik için hibrid bir MCDM yöntemi kullanarak yeşil termal enerji ekipmanı tedarikçisinin seçilmesi, Chauhan, Singh, Tiwari, Patnaik ve Thakur (2017) havayolunda kullanılan jetlerin yakıt performanslarının incelenmesi, Li, Wang, Liu, Xin, Yang ve Gao (2011) kömür madenlerinde güvenlik değerlendirilmesi, Huang (2008) iletişim sistemlerinin seçimi, Hong-Yan (2004) inşaat projelerinin değerlendirilmesi, Gao ve Xi (2008) endüstrilerin inovasyon kapasitelerinin analiz edilmesi, Akyene (2012) cep telefonlarının değerlendirilmesi, Rezaei, Ghazanfari ve Kazemi (2014) kırsal-kentsel alan bütünleşme performansları ve bölgesel farklılıkların analizi, Wang, Zhan ve Qiu (2006) tesis yönetimi modellerinin değerlendirilmesi, Tewari, Prakash ve Khanduja (2009) otomobil seçimlerinin değerlendirilmesi, Meng ve Hu (2009) ile Zhang, Liang ve Liu (2007) su kalitesinin değerlendirilmesi, Li-juan (2002) tedarik zinciri perspektifinde tedarikçilerin değerlendirilmesi, Zhang ve Luo (2014) endüstriyel kümelerin rekabet düzeyinin analizi, Zhang ve Zhou (2014) hava hedef tehdit dizisinin değerlendirilmesi, Chen, Meng ve He (2011) bölgesel kentleşme düzeyinin değerlendirilmesi, Sun, Miao ve Yang (2017) gelişmekte olan stratejik sektörlerde yeşil teknoloji yeniliğinin ekolojik-ekonomik verimlilik değerlendirmesi, Zhenghua ve Wendong (2004) lojistik gelişmelerin rekabet koşullarının analizi, Yin, Sh1 ve L1 (2011) bölgesel sistemin gelişim hassasiyetinin analizi ve değerlendirilmesi, Sun, Zhang ve Liu (2016) web hizmeti kalitesinin değerlendirilmesi, Aalami, Moghaddam ve Yousefi (2010) enerji piyasasında talep cevaplama performansının incelenmesi gibi çalışmalar entegre entropi ve TOPSIS yöntemlerini kullanmışlardır.

Bunların dışında söz konusu model kullanarak gerçekleştirilen çok sayıda çalışmaya rastlanmaktadır. Genel olarak değerlendirildiğinde çekici araç seçimine ilişkin söz konusu model veya yöntemlerin kullanıldığı bir çalışma görülmediği gibi, daha da önemlisi bir başka çok kriterli karar verme yöntemi ya da hibrid bir modelin kullanılarak çekici araç seçimlerinin analiz edildiği bir çalışmaya rastlanılmamıştır. Dolayısıyla söz konusu çalışma literatürde görülen boşluğu gidermeye yönelik önemli katkılar sağlayabileceği gibi, karar vericiler tarafından son derece kolay bir biçimde uygulanabilecek bir çerçeve de ortaya koymaktadır.

\section{Materyal ve Metot}

$\mathrm{Bu}$ çalışmada taşımacılık faaliyeti yürüten işletmeler ve lojistik hizmet üreticiler ile taşımacılık operatörlerinin operasyonlarda kullanacakları araçları tercih ederlerken dikkate aldıkları seçim kriterleri ile karar alternatiflerinin analiz edilmesi ve en uygun aracın belirlenebilmesi için Analitik Hiyerarşi Prosesi (AHP), Entropi ve TOPSIS yöntemleri entegre edilerek oluşturulan hibrid bir model önerilmiştir. Model toplamda on dört adımdan oluşmakta, AHP yönteminin uygulama adımlarının kullanıldığı ilk dört adımında seçim kriterleri, karar alternatifleri ve sayısal niteliğe sahip olmayan faktörlerin ölçülebilir değerlere dönüştürülebilmesi için kullanılacak anketlerin yöneltileceği karar alıcılar belirlenmiştir. Aynı zamanda bu süreçte sayısal niteliğe sahip 'olmayan faktörlerin ağırlıkları hesaplanmıştır. 
Şekil 1. Hibrid modelin uygulama adımları

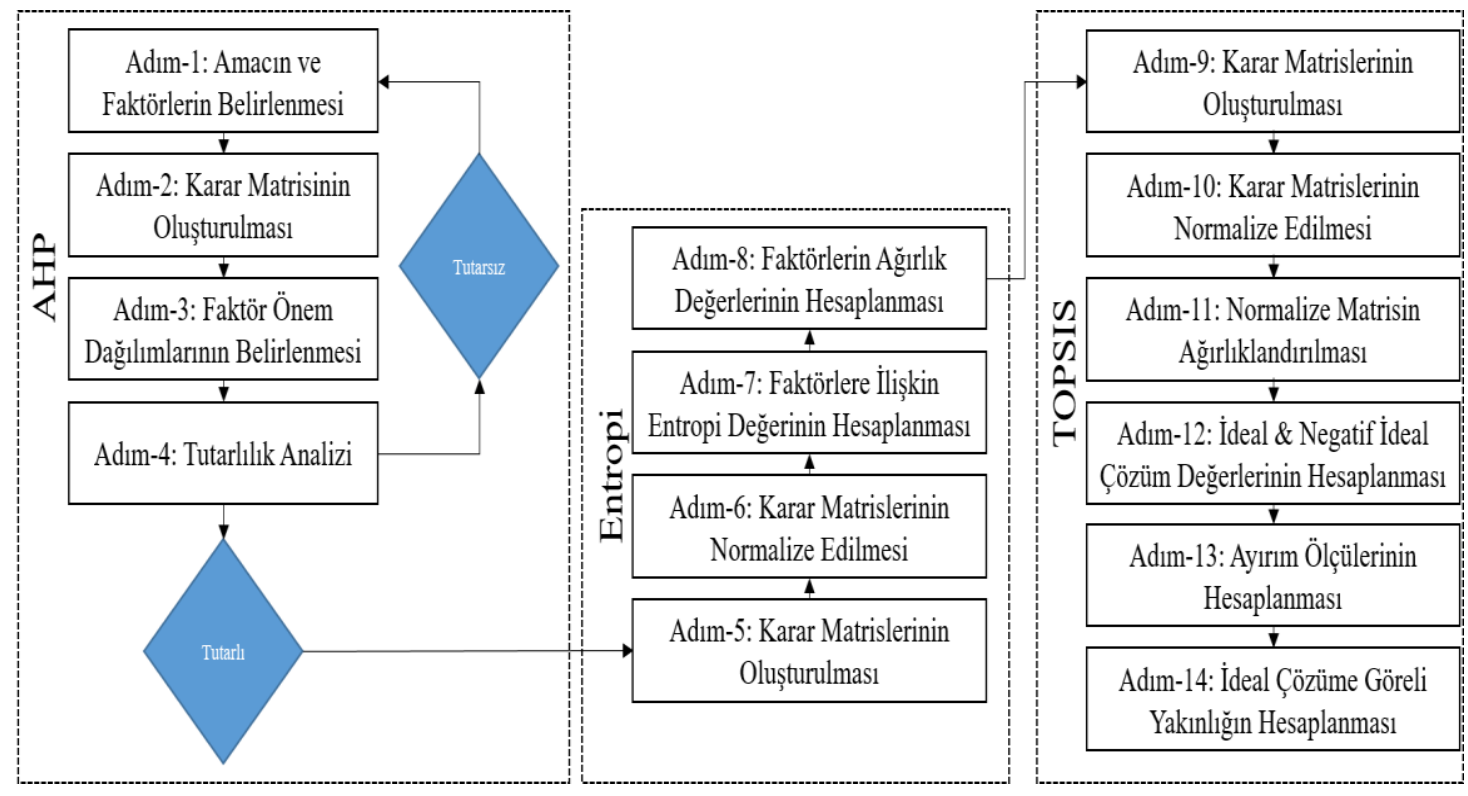

İkinci dört adımda entropi yönteminin uygulama adımları kullanılırken, belirlenen bütün faktörlerin ağırlık değerleri hesaplanmış, göreli olarak önem dereceleri belirlenmiştir. Sonraki altı adımda TOPSIS yönteminin uygulama adımları kullanılarak seçilen karar alternatiflerinin girdi ve çıktı değerleri ile birlikte verimlilik ve performans skorları da hesaplanmıştır. Modeli ilişkin akış süreci şekil 1 de gösterilmektedir.

\subsection{Adım-1: Amacın ve Faktörlerin Belirlenmesi}

Seçilen modelin birinci adımında oluşturulan uzmanlar kurulu ile birlikte öncelikle problem tanımlanmakta, ardından çekici araç seçimine etki eden faktörlerin yanı sıra, değerlendirilecek karar noktaları tespit edilmektedir. Aynı zamanda bu süreçte belirlenen seçim kriterlerinin sayısal ölçekte değer alıp almadıkları da saptanmaktadır. Seçim kriterleri ve karar noktaları belirlendikten sonra, faktörler arasındaki hiyerarşi ve ilişkileri göstermek üzere bir hiyerarşik model oluşturulmaktadır.

Şekil 2. AHP Hiyerarşik Modeli

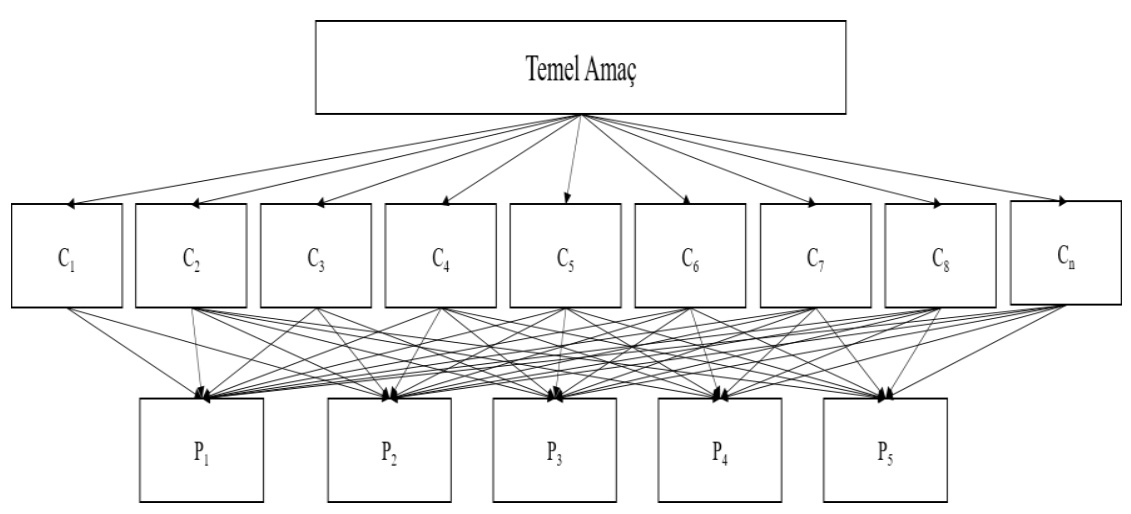

$\mathrm{Bu}$ sürecin sonunda sayısal verilere sahip olmayan faktörlerin sayısal ölçekte tanımlanması için karar alıcılara yöneltilecek ikili karşılaştırma soruları hazırlanmakta ve karar alıcılara yöneltilmektedir. 


\subsection{Adım-2: Karar Matrisinin Olușturulması}

Uzmanlar kurulu tarafindan belirlenen seçim kriterleri içerisinde sayısal değerlere sahip olmayan faktörlerin sayısal değerlere dönüştürülebilmesi için Tablo-1 de gösterildiği gibi Saaty (1986) 1-9 karşılaştırma ölçeği çerçevesinde hazırlanan ikili karşılaştırma soruları karar alıcılara yöneltilmiştir. Ardından eşitlik 1 kullanılarak, her bir ikili karşılaştırma için elde edilen cevapların geometrik ortalaması alınmış, oluşturulacak ikili karşılaş̧ırma matrisi A’nın eleman değerleri belirlenmiştir.

$$
x=\sqrt[n]{a_{1} x a_{2} \times a_{3} \ldots x a_{n}}
$$

Oluşturulan nxn boyutlu kare matrisin bütün köşe elemanları her bir faktörün kendisi ile karşılaştırılması anlamına geldiği için bir değerini almakta, bir i faktörünün $\mathrm{j}$ faktörüne göre hesaplanan önem değerinin tersi $\mathrm{j}$ faktörünün i faktörüne göre önem değerini göstermektedir. Dolayısıyla her iki faktörün önem derecelerini karşılıklı olarak belirleyebilmek için eşitlik 2 den faydalanılmaktadir.

$$
a_{j i}=\frac{1}{a_{i j}}
$$

Tablo 1. İkili karşılaştırma ölçeği

\begin{tabular}{lll}
\hline Önem & Tanım & \multicolumn{1}{c}{ Açılama } \\
\hline 1 & Eşit önemli & i’nin j ye eşit olması \\
3 & Çok az önemli & i’nin j den çok az önemli olması \\
5 & Kuvvetli derecede önemli & i'nin j den kuvvetli derecede önemli olması \\
7 & Çok kuvvetli derecede önemli & i’nin j den çok kuvvetli derecede önemli olması \\
9 & Mutlak önemli & i’nin j den mutlak önemli olması \\
\hline
\end{tabular}

Kaynak: Saaty; 1986: 843

Nihai olarak karar matrisinin tüm eleman değerleri belirlendikten sonra eşitlik 3 de gösterildiği gibi matris A oluşturulmaktadır.

$$
A=\left[\begin{array}{cccc}
a_{11} & a_{12} & \ldots & a_{1 n} \\
a_{21} & a_{22} & \ldots & a_{2 n} \\
\cdot & & & \cdot \\
\cdot & & & \cdot \\
\cdot & & & \cdot \\
a_{n 1} & a_{n 2} & \ldots & a_{n n}
\end{array}\right]
$$

\subsection{Adım-3: Faktör Önem Dağılımlarının Belirlenmesi}

Bu uygulama adımı temelde iki alt süreçten oluşmaktadır. Birinci aşamada daha önceki adımda elde edilen ikili karşılaştırma matrisi eşitlik 4 yardımı ile normalize edilerek, normalize matris C oluşturulmaktadır.

$$
b_{i j}=\frac{a_{i j}}{\sum_{i=1}^{n} a_{i j}}
$$

Bunun için ikili karşılaştırma matrisinin her bir elemanı kendi sütun toplamına bölünerek eşitlik 5 de gösterilen ve normalize değerlerden oluşan b sütun vektörleri elde edilmekte, ardından bu vektörler birleştirilerek eşitlik 6 de gösterilen normalize matris $\mathrm{C}$ oluşturulmaktadır. 


$$
\begin{aligned}
b_{i} & =\left[\begin{array}{c}
b_{11} \\
b_{21} \\
\cdot \\
\cdot \\
\cdot \\
b_{n 1}
\end{array}\right] \\
C & =\left[\begin{array}{cccc}
c_{11} & c_{12} & \ldots & c_{1 n} \\
c_{21} & c_{22} & \ldots & c_{2 n} \\
\cdot & & & \cdot \\
\cdot & & & \cdot \\
\cdot & & & \cdot \\
c_{n 1} & c_{n 2} & \ldots & c_{n n}
\end{array}\right]
\end{aligned}
$$

İkinci alt aşamada daha önce elde edilen normalize matrisin her bir satırında bulunan değerlerin aritmetik ortalaması hesaplanmaktadır. Eşitlik 7 de görüldüğü gibi normalize matris C'nin satır toplamı faktör sayısına bölünmektedir.

$$
w_{i}=\frac{\sum_{j=1}^{n} c_{i j}}{n}
$$

$\mathrm{Bu}$ sürecin sonunda bütün satırların aritmetik ortalaması alındıktan sonra eşitlik 8 de gösterilen vektör w elde edilmektedir.

$$
w_{i}=\left[\begin{array}{c}
w_{11} \\
w_{21} \\
\cdot \\
\cdot \\
\cdot \\
w_{n 1}
\end{array}\right]
$$

\subsection{Adım-4: Tutarlılık Analizi}

Faktörlerin önem değerleri hesaplandıktan sonra, gerçekleştirilen değerlendirmenin tutarlı olup olmadığı gözden geçirilmektedir. Tutarlılık analizi toplamda dört aşamadan oluşmaktadır. Eşitlik 9 kullanılarak, ikili karşılaştırma matrisi A'nın elamanları ile hesaplanan w vektörünün eleman değerleri ayrı ayrı çarpılarak D matrisi elde edilmektedir.

$$
D=\left[\begin{array}{cccc}
a_{11} & a_{12} & \ldots & a_{1 n} \\
a_{21} & a_{22} & \ldots & a_{2 n} \\
\cdot & \cdot & . & \cdot \\
a_{n 1} & a_{n 2} & \cdot & a_{n n}
\end{array}\right] x\left[\begin{array}{c}
w_{1} \\
w_{2} \\
w_{3} \\
w_{n}
\end{array}\right]=\left[\begin{array}{cccc}
d_{11} & d_{12} & \ldots & d_{1 n} \\
d_{21} & d_{22} & \ldots & d_{2 n} \\
\cdot & \cdot & . & \cdot \\
d_{n 1} & d_{n 2} & . & d_{n n}
\end{array}\right]
$$

Bir sonraki aşamada D matrisinin bütün elemanları w vektörüne bölünerek e sütun vektörü oluşturulmaktadır. Hesaplanan e değeri öz değer olarak tanımlanmaktadır. Bu değerin hesaplanması için eşitlik 10 kullanılmaktadır.

$$
e_{i}=\frac{d_{i}}{w_{i}}
$$

Eşitlik 11 kullanılarak, sütün vektörü e'nin aritmetik ortalaması alındığında karşılaştırma için kullanılan $\lambda$ maks değeri hesaplanmaktadır. 


$$
\lambda_{\max }=\frac{\sum_{i=1}^{n} e_{i}}{n}
$$

Ardından eşitlik 12 kullanılarak tutarlılık göstergesi CI hesaplanmaktadır.

$$
C I=\frac{\lambda_{\max }-n}{n-1}
$$

Son olarak eşitlik 13 kullanılarak tutarlılık rasyosu CR hesaplanmaktadır. Random İndeks olarak adlandırılan R1 değeri Tablo 2 den elde edilmektedir.

$$
C R=\frac{C I}{R I}
$$

Hesaplanan CR değerinin 0.10 dan düşük olması halinde değerlendirme tutarlı olarak kabul edilmekte ve bir sonraki adıma geçilmektedir. CR değerinin 0,10 dan yüksek olmas1 durumunda tutarsız olarak kabul edilip, başlangıç adımına dönülerek elde edilen değerler tekrar gözden geçirilmekte, gerekli olması halinde bütün süreç yeniden tasarımlanabilmektedir.

Tablo 2.Rassallık göstergeleri

\begin{tabular}{cccccccccc}
\hline $\mathrm{n}$ & $\mathrm{RI}$ & $\mathrm{n}$ & $\mathrm{RI}$ & $\mathrm{n}$ & $\mathrm{RI}$ & $\mathrm{n}$ & $\mathrm{RI}$ & $\mathrm{n}$ & $\mathrm{RI}$ \\
\hline 1 & 0,00 & 4 & 0,90 & 7 & 1,32 & 10 & 1,49 & 13 & 1,56 \\
2 & 0,00 & 5 & 1,12 & 8 & 1,41 & 11 & 1,51 & & \\
3 & 0,58 & 6 & 1,24 & 9 & 1,45 & 12 & 1,48 & & \\
\hline
\end{tabular}

\subsection{Adım-5: Karar Matrislerinin Oluşturulması}

Beşinci uygulama adımı dört adımdan oluşan Entropi yönteminin (Mandal ve Mondal; 2016: 3) ilk aşamasıdır. Bu aşamada eşitlik 14 de gösterilen nxm boyutlu karar matrisi oluşturulurken, satır kısmında yer alan faktörler karar noktalarım, sütün kısmında yer alan faktörler ise seçim kriterlerini göstermektedir.

$$
X=\left[\begin{array}{cccc}
x_{11} & x_{12} & \ldots & x_{1 n} \\
x_{21} & x_{22} & \ldots & x_{2 n} \\
\cdot & & & \cdot \\
\cdot & & & \cdot \\
\cdot & & & \cdot \\
x_{m 1} & x_{m 2} & \ldots & x_{m n}
\end{array}\right]
$$

\subsection{Adım-6: Karar Matrislerinin Normalize Edilmesi}

Altıncı aşamada eşitlik 15 kullanılarak, karar matrisinin her bir elemanı kendi sütun toplamına bölünerek normalize edilmektedir.

$$
x^{*}{ }_{i j}=\frac{x_{i j}}{\sum_{i=1}^{m} x_{i j}}
$$

Bütün matris elemanları normalize edildikten sonra eşitlik 16 da görüldüğü gibi normalize matris $\mathrm{X}^{*}$ oluşturulmaktadır. 


$$
X^{*}=\left[\begin{array}{cccc}
x_{11}^{*} & x_{12}^{*} & \ldots & x_{1 n}^{*} \\
x_{21}^{*} & x_{22}^{*} & \ldots & x_{2 n}^{*} \\
\cdot & & & \cdot \\
\cdot & & & \cdot \\
\cdot & & & \cdot \\
x_{m 1}^{*} & x_{m 2}^{*} & \ldots & x_{m n}^{*}
\end{array}\right]
$$

\subsection{Adım-7: Faktörlere İlişsin Entropi Değerinin Hesaplanması}

Eşitlik 17 yardımıyla her bir normalize matris elamanı kendi logaritmik değeri ile çarpılarak söz konusu matris elemanının entropi değeri elde edilmektedir.

$$
e_{i j}=x_{i j}^{*} \cdot\left((\ln ) x_{i j}^{*}\right)
$$

Matris elemanlarının tümü için entropi değeri hesaplandıktan sonra, eşitlik 18 de gösterildiği gibi, elemanların entropi değerlerini gösteren matris E oluşturulmaktadır.

$$
E=\left[\begin{array}{cccc}
e_{11} & e_{12} & \ldots & e_{1 n} \\
e_{21} & e_{22} & \ldots & e_{2 n} \\
\cdot & & & \cdot \\
\cdot & & & \cdot \\
\cdot & & & \cdot \\
e_{m 1} & e_{m 2} & \ldots & e_{m n}
\end{array}\right]
$$

Entropi değerlerini gösteren matris E oluşturulduktan sonra her bir seçim kriteri için entropi değerlerini hesaplamak üzere eşitlik 19 kullanılmaktadır. E matrisinin her bir sütun değerlerinin toplamı faktör sayısının logaritmik değerinin 1'e bölündüğünde hesaplanan değer ile çarpılarak her bir faktör için entropi değeri hesaplanabilmektedir.

$$
E_{i j}{ }^{*}=\left(\frac{-1}{\ln (m)}\right) \cdot \sum_{i=1}^{m}\left[x_{i j}{ }^{*} \cdot \ln x_{i j}{ }^{*}\right] ; \forall j
$$

Yedinci adımın son aşamasında dij olarak tanımlanan belirsizlik değeri (Triantaphyllou; 2000: 44) eşitlik 20 kullanılarak hesaplanmaktadır.

$$
d_{i j}=1-E_{i j}{ }^{*} ; \forall j
$$

\subsection{Adım-8: Faktörlerin Ăgırlık Değerlerinin Hesaplanması}

Entropi yönteminin uygulama adımlarının kullanıldığı bu aşamanın son adımında faktörlerin ağırlık değerleri eşitlik 21 kullanılarak hesaplanmaktadır. Her bir faktör için ağırlık değeri faktöre ilişkin belirsizlik değeri, toplam belirsizlik değerine bölünerek elde edilmektedir.

$$
w_{i j}=\frac{d_{i j}}{\sum_{i=1}^{m} d_{i j}} ; \forall j
$$

\subsection{Adım-9: Karar Matrislerinin Oluşturulması}

Seçilen modelin dokuzuncu, TOPSIS yönteminin ise birinci adımında adım 5'e benzer şekilde karar matrisi X oluşturulmaktadır (Zavadskas vd.;2008: 85-93). Matris X; mxn boyutlu bir matris olup, seçim kriterleri ile karar alternatiflerini birlikte gösteren bir matristir. Eşitlik 14 de gösterildiği şekilde oluşturulmaktadır. 


\subsection{Adım-10: Karar Matrislerinin Normalize Edilmesi}

Karar matrisi A'nın her bir elamanı eşitlik 22 yardımı ile normalize edilmektedir. Bunun için her bir matris elemanı kendi sütunu için hesaplanmış geometrik ortalama değerine bölünerek normalize edilmektedir.

$$
r_{i j}=\frac{x_{i j}}{\sqrt{\sum_{k=1}^{m} x_{k j}^{2}}}
$$

Normalizasyon işlemlerinin ardından eşitlik 23 de gösterilen normalize matris $\mathrm{R}$ oluşturulmaktadır.

$$
R=\left[\begin{array}{cccc}
r_{11} & r_{12} & \ldots & r_{1 n} \\
r_{21} & r_{22} & \ldots & r_{2 n} \\
\cdot & & & \cdot \\
\cdot & & & \cdot \\
\cdot & & & \cdot \\
r_{m 1} & r_{m 2} & \ldots & r_{m n}
\end{array}\right]
$$

\subsection{Adım-11: Normalize Matrisin Ağırlıklandırılması}

Onuncu adımda elde edilen normalize matris $\mathrm{R}$ ile Adım 8'de elde edilen faktör ağırlıkları çapılarak normalize matris ağırlıklandırılmaktadır. İşlemin ardından eşitlik 24 de gösterilen ağırlıklandırılmış normalize matris $\mathrm{V}$ oluşturulmaktadır.

$$
V=\left[\begin{array}{cccc}
w_{1} r_{11} & w_{2} r_{12} & \ldots & w_{n} r_{1 n} \\
w_{1} r_{21} & w_{2} r_{22} & \ldots & w_{n} r_{2 n} \\
\cdot & & & \cdot \\
\cdot & & & \cdot \\
\cdot & & & \cdot \\
w_{1} r_{m 1} & w_{2} r_{m 2} & \ldots & w_{n} r_{m n}
\end{array}\right]
$$

\subsection{Adım-12: İdeal ve Negatif İdeal Çözüm Değerlerinin Hesaplanması}

$\mathrm{Bu}$ adımda ideal ve negatif ideal çözüm değerleri hesaplanmaktadır. Herhangi bir faktör için beklenen en yüksek değeri alması ise ideal, aynı faktör için en düşük değer negatif ideal çözüm olarak ifade edilmektedir. Buna karşılık faktör negatif yönlü bir faktör ise tam tersi olarak en düşük değer ideal, en yüksek değer ise negatif ideal çözüm anlamına gelmektedir. Eşitlik 25 de gösterildiği gibi ideal çözümler elde edilmektedir.

$$
A^{*}=\left\{\left(\max _{i} v_{i j} \mid j \in J\right),\left(\min _{i} v_{i j} \mid j \in J^{\prime}\right\}\right.
$$

Elde edilen ideal çözüm kümesi $\mathrm{A}^{*}=\left\{\mathrm{v}_{1}{ }^{*}, \mathrm{v}_{2}{ }^{*}, \ldots, \mathrm{V}_{\mathrm{n}}{ }^{*}\right\}$ olarak gösterilebilir. Negatif ideal çözüm ise beklenen en yüksek ya da en küçük değerlere göre, faktörün alacağı en kötü skor olarak tanımlanır. Negatif ideal çözüm aşağıdaki gibi hesaplanabilir.

$$
A^{-}=\left\{\left(\min _{i} v_{i j} \mid j \in J\right),\left(\max _{i} v_{i j} \mid j \in J^{\prime}\right\}\right.
$$


Negatif ideal çözüm kümesi $\mathrm{A}^{-}=\left\{\mathrm{v}_{1}^{-}, \mathrm{v}_{2}^{-}, \ldots, \mathrm{v}_{\mathrm{n}}^{-}\right\}$şeklinde oluşturulabilmektedir. İdeal ve negatif ideal çözümlerde j en yüksek değeri, $\mathrm{j}$ 'ise en küçük değeri göstermektedir.

\subsection{Adım-13: Ayırım Ölçülerinin Hesaplanması}

$\mathrm{Bu}$ adımda her bir faktörün ideal ve negatif ideal çözümden uzaklıkları belirlenmektedir. Eşitlik 27 yardımıyla faktörlerin ideal çözümden uzaklıkları hesaplanırken, eşitlik 28 kullanılarak faktörlerin negatif ideal çözümden uzaklıkları hesaplanmaktadır.

$$
\begin{aligned}
& S_{i}^{*}=\sqrt{\sum_{j=1}^{n}\left(v_{i j}-v_{j}^{*}\right)^{2}} \\
& S_{i}^{-}=\sqrt{\sum_{j=1}^{n}\left(v_{i j}-v_{j}^{-}\right)^{2}}
\end{aligned}
$$

\subsection{Adım-14: İdeal Çözüme Göreli Yakınlığın Hesaplanması}

Eşitlik 29 kullanılarak her bir karar noktası için ideal çözüme yakınlık hesaplanabilmektedir.

$$
C_{i}^{*}=\frac{S_{i}^{-}}{S_{i}^{-}+S_{i}^{*}}
$$

Elde edilen $\mathrm{C}_{\mathrm{i}}^{*}$ değerinin 1'e yakın olması durumunda ideal, 0'a yaklaşması halinde negatif ideal çözüme yaklaşıldığı söylenebilmektedir. Bütün faktörler için söz konusu değer hesaplandıktan sonra en yüksek değerden başlanarak karar alternatifleri sıralanmaktadır. En yüksek değeri alan karar alternatifi en iyi karar noktası olarak tanımlanmaktadır.

\section{Sayısal Analiz}

Toplamda 14 adımdan oluşan hibrid model kullanılarak, uluslararası karayolu taşıma faaliyeti yürüten lojistik hizmet üreten işletmelerin çekici araç seçimlerine ilişkin karar alma süreçleri analiz edilmiştir. Bu kapsamda daha rasyonel, gerçekçi ve uygulanabilir sonuçlar elde etmek amacıyla yedi kişiden oluşan uzmanlar kurulu oluşturulmuş, uzmanlar kurulu ile yapılan toplantılarda çekici araç seçimine etki eden faktörlerin yanı sıra, analize tabi tutulacak karar alternatifleri saptanmıştır.

\subsection{Adım-1: Amacın ve Faktörlerin Belirlenmesi}

Uzmanlar kurulu ile yapılan toplantılarda belirlenen seçim kriterleri ve karar noktaları doğrultusunda Şekil 1 de görüldüğü gibi hiyerarşik model oluşturulmuştur. 
Şekil 3. Çekici araç seçimi için hiyerarşik model

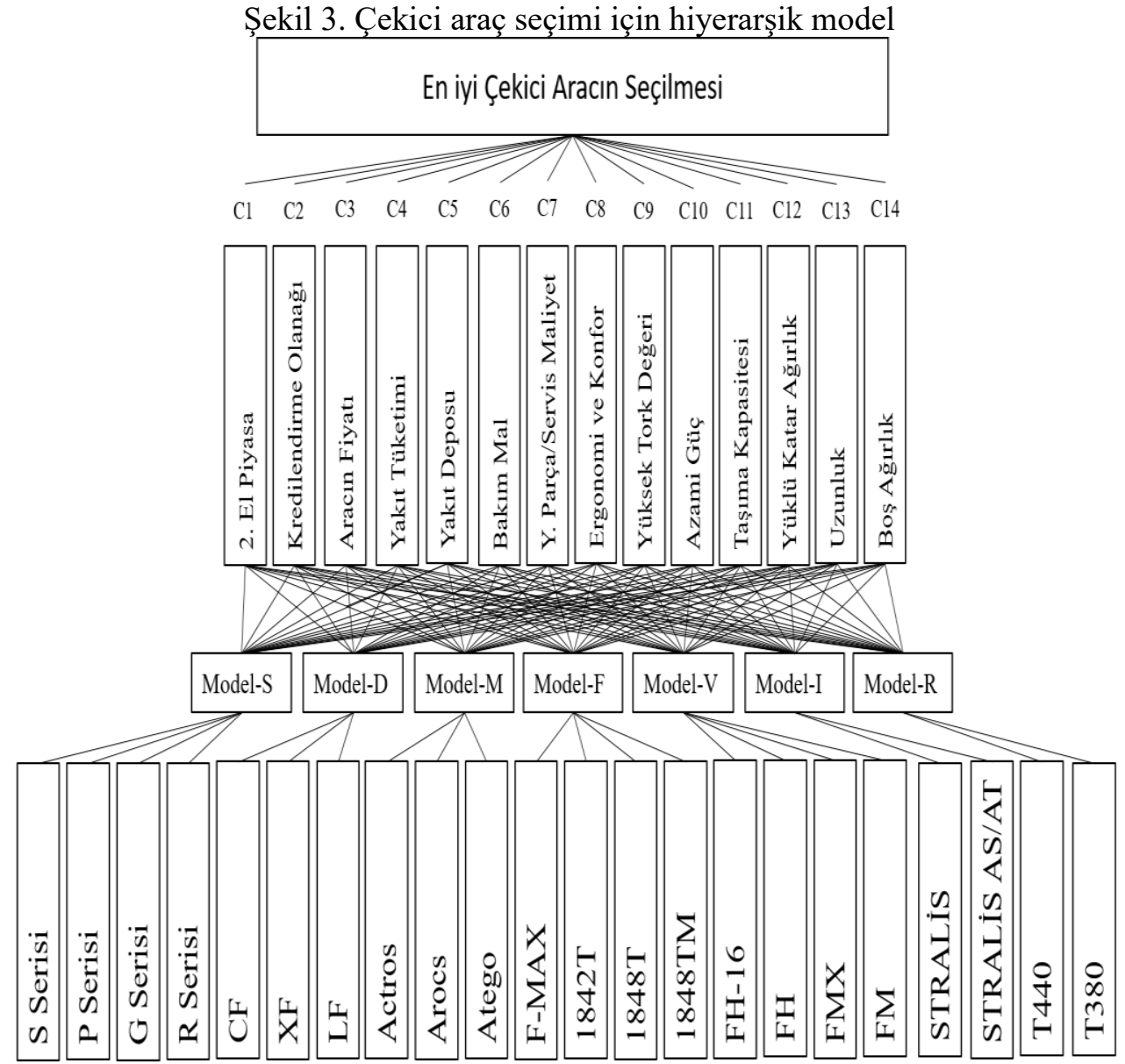

Hiyerarşik model oluşturulduktan sonra, belirlenen seçim kriterleri ve karar noktaları arasında sayısal ölçeğe sahip olmayan faktörler belirlenmiştir. Bütün faktörler sayısal değerlere sahipken sadece "ergonomi ve konfor olarak belirlenen seçim kriteri için sayısal değer mevcut olmayıp, tümüyle kullanıcıların kişisel yargılarına dayanan bir faktör konumundadır. $\mathrm{Bu}$ nedenle söz konusu faktör için sayısal değer belirleyebilmek üzere AHP yaklaşımın adımları kullanılarak, ikili karşılaştırma soruları oluşturulmuştur.

\subsection{Adım-2: İkili Karşılaştırma Matrisinin Oluşturulması}

Konfor ve ergonomi kriteri ile ilgili olarak karar alıcılardan öncelikle markaları karşılaştırmaları istenmiş, ardından her markanın alt modelleri kendi aralarında karşılaştırmaya tabi tutulmuştur. Ardından belirlenen karar alıcılara bu sorular yöneltilerek her bir karşılaştırma sorusu için yanıtlar elde edilmiş ve eşitlik 1 kullanılarak söz konusu faktör için oluşturulan ikili karşılaştırma matrisi A’nın sayısal değerleri elde edilmiştir.

\begin{tabular}{|c|c|c|c|c|c|c|c|}
\hline & $P_{1}$ & $P_{2}$ & $P_{3}$ & $P_{4}$ & $P_{5}$ & $P_{6}$ & $P_{7}$ \\
\hline$P_{1}$ & {$[1,00$} & 2,00 & 2,00 & 8,00 & 2,00 & 7,00 & 8,00 \\
\hline$P_{2}$ & 0,50 & 1,00 & 2,00 & 3,00 & 2,00 & 2,00 & 3,00 \\
\hline$P_{3}$ & 0,50 & 0,50 & 1,00 & 8,13 & 3,00 & 3,00 & 3,00 \\
\hline & 0,13 & 0,33 & 0,12 & 1,00 & 2,00 & 1,00 & 1,00 \\
\hline & 0,50 & 0,50 & 0,33 & 0,50 & 1,00 & 2,00 & 3,00 \\
\hline$P_{6}$ & 0,14 & 0,50 & 0,33 & 1,00 & 0,50 & 1,00 & 2,00 \\
\hline & 0,13 & 0,33 & 0,33 & 1,00 & 0,33 & 0,50 & 1,00 \\
\hline & 2,89 & 5,17 & 6,12 & 22,63 & 10,83 & 16,50 & 21,0 \\
\hline
\end{tabular}




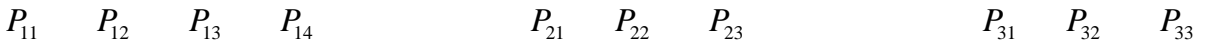

$$
\begin{aligned}
& P_{11}\left[\begin{array}{llll}
1,00 & 1,51 & 1,46 & 1,49
\end{array}\right] \\
& \begin{array}{l|llll}
P_{12} & 0,66 & 1,00 & 0,74 & 1,02
\end{array} \\
& A_{2}=P_{13} \quad 0,69 \quad 1,35 \quad 1,00 \quad 1,30 \\
& \begin{array}{l|llll}
P_{14} & 0,67 & 0,98 & 0,77 & 1,00
\end{array} \\
& \sum\left[\begin{array}{llll}
3,02 & 4,85 & 3,96 & 4,82
\end{array}\right] \\
& A_{3}=\underset{P_{22}}{P_{23}}\left[\begin{array}{lll}
P_{23} \\
\sum
\end{array}\left[\begin{array}{lll}
1,00 & 1,20 & 0,80 \\
0,83 & 1,00 & 1,50 \\
1,25 & 0,67 & 1,00 \\
3,08 & 2,87 & 3,30
\end{array}\right]\right. \\
& A_{4}=P_{32}^{P_{33}} P_{33}\left[\begin{array}{lll}
1,00 & 1,20 & 1,20 \\
0,83 & 1,00 & 1,50 \\
0,83 & 0,67 & 1,00 \\
2,67 & 2,87 & 3,70
\end{array}\right] \\
& \begin{array}{llll}
P_{41} & P_{42} & P_{43} & P_{44}
\end{array} \\
& P_{41}\left[\begin{array}{llll}
1,00 & 0,80 & 1,20 & 0,80
\end{array}\right] \\
& \begin{array}{l|llll}
P_{42} & 1,25 & 1,00 & 0,74 & 1,02
\end{array} \\
& A_{5}=P_{43} \quad 0,83 \quad 1,35 \quad 1,00 \quad 1,30 \\
& \begin{array}{l|llll}
P_{44} & 1,25 & 0,98 & 0,77 & 1,00
\end{array} \\
& \sum\left[\begin{array}{llll}
4,33 & 4,13 & 3,71 & 4,12
\end{array}\right]
\end{aligned}
$$

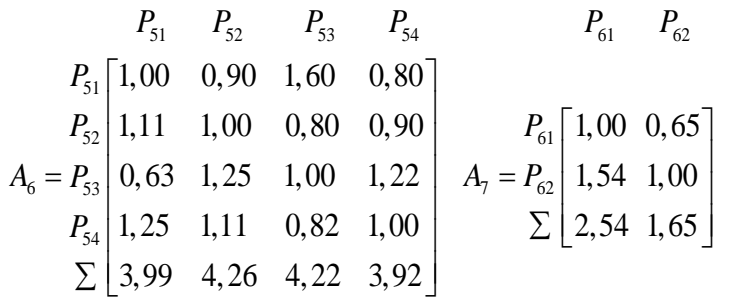

$$
\begin{aligned}
& A_{8}=P_{72}^{P_{72}}\left[\begin{array}{ll}
1,00 & 1,60 \\
\sum, 63 & 1,00 \\
1,63 & 2,60
\end{array}\right]
\end{aligned}
$$

\subsection{Adım-3: Faktör Önem Dağılımlarının Belirlenmesi}

İkinci adımda elde edilen karar matrisleri eşitlik 4 kullanılarak normalize edilmiş, normalize $\mathrm{C}$ matrisleri oluşturulmuştur.

$$
\begin{aligned}
& \begin{array}{ccccccc}
P_{1} & P_{2} & P_{3} & P_{4} & P_{5} & P_{6} & P_{7}
\end{array} \\
& P_{1}\left[\begin{array}{lllllll}
1,00 & 2,00 & 2,00 & 8,00 & 2,00 & 7,00 & 8,00
\end{array}\right] \\
& \left.\begin{array}{l|lllllll}
P_{2} & 0,50 & 1,00 & 2,00 & 3,00 & 2,00 & 2,00 & 3,00
\end{array}\right] \\
& \begin{array}{l|lllllll}
P_{3} & 0,50 & 0,50 & 1,00 & 8,13 & 3,00 & 3,00 & 3,00
\end{array} \\
& C_{1}=\begin{array}{l|llllllll}
P_{4} & 0,13 & 0,33 & 0,12 & 1,00 & 2,00 & 1,00 & 1,00 \\
P_{5} & 0,50 & 0,50 & 0,33 & 0,50 & 1,00 & 2,00 & 3,00
\end{array} \\
& \begin{array}{l|lllllll}
P_{6} & 0,14 & 0,50 & 0,33 & 1,00 & 0,50 & 1,00 & 2,00
\end{array} \\
& \begin{array}{l|lllllll}
P_{7} & 0,13 & 0,33 & 0,33 & 1,00 & 0,33 & 0,50 & 1,00
\end{array} \\
& \Sigma\left[\begin{array}{llllllll}
2,89 & 5,17 & 6,12 & 22,63 & 10,83 & 16,50 & 21,00
\end{array}\right]
\end{aligned}
$$

$$
\begin{aligned}
& \begin{array}{llll}
P_{11} & P_{12} & P_{13} & P_{14}
\end{array} \\
& P_{11}\left[\begin{array}{llll}
1,00 & 1,51 & 1,46 & 1,49
\end{array}\right. \\
& \begin{array}{l|llll}
P_{12} & 0,66 & 1,00 & 0,74 & 1,02
\end{array} \\
& C_{2}=P_{13} \mid \begin{array}{lllll}
0,69 & 1,35 & 1,00 & 1,30
\end{array} \\
& \begin{array}{l|llll}
P_{14} & 0,67 & 0,98 & 0,77 & 1,00
\end{array} \\
& \sum\left[\begin{array}{llll}
3,02 & 4,85 & 3,96 & 4,82
\end{array}\right] \\
& \begin{array}{lll}
P_{21} & P_{22} & P_{23}
\end{array} \\
& C_{3}=\underset{P_{22}}{P_{23}}\left[\begin{array}{ccc}
P_{21} \\
\sum
\end{array}\left[\begin{array}{lll}
1,00 & 1,20 & 0,80 \\
0,83 & 1,00 & 1,50 \\
1,25 & 0,67 & 1,00 \\
3,08 & 2,87 & 3,30
\end{array}\right]\right. \\
& C_{4}=\underset{P_{33}}{P_{33}} \stackrel{P_{33}}{\sum}\left[\begin{array}{lll}
1,00 & 1,20 & 1,20 \\
0,83 & 1,00 & 1,50 \\
0,83 & 0,67 & 1,00 \\
2,67 & 2,87 & 3,70
\end{array}\right]
\end{aligned}
$$

$P_{41} \quad P_{42} \quad P_{43} \quad P_{44}$

$$
\begin{array}{llll}
P_{51} & P_{52} & P_{53} & P_{54}
\end{array}
$$$$
P_{61} \quad P_{62}
$$$$
P_{71} \quad P_{72}
$$

$$
\left.\begin{array}{l}
P_{51} \\
P_{52}
\end{array} \begin{array}{ccccc}
1,00 & 0,90 & 1,60 & 0,80 \\
1,11 & 1,00 & 0,80 & 0,90
\end{array}\right]
$$$$
P_{42} \quad 1,25 \quad 1,00 \quad 0,74 \quad 1,02
$$$$
C_{5}=P_{43} \quad 0,83 \quad 1,35 \quad 1,00 \quad 1,30 \quad C_{6}
$$

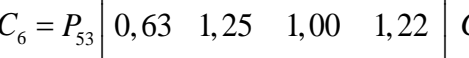

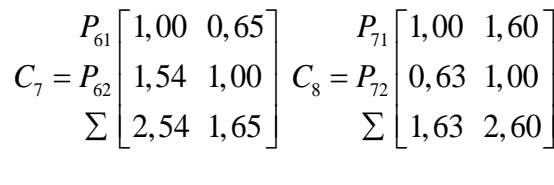

$$
\begin{aligned}
& P_{54}\left[\begin{array}{llll}
1,25 & 1,11 & 0,82 & 1,00 \\
3,99 & 4,26 & 4,22 & 3,92
\end{array}\right]
\end{aligned}
$$$$
\sum\left[\begin{array}{llll}
4,33 & 4,13 & 3,71 & 4,12
\end{array}\right]
$$

Sürecin devamında eşitlik 7 kullanılarak her bir $\mathrm{C}$ matrisi için normalize matris satır değerlerinin ortalamaları alınmış, ergonomi ve konfor faktörü için her bir karar noktası ve alt karar noktası için göreli ağılık değeri hesaplanmıştır. 


$$
\left.\begin{array}{rl}
P_{1} & 0,3432 \\
P_{2} & 0,1820 \\
P_{3} & 0,1991 \\
w_{1}= & P_{4} \\
P_{5} & 0,0664 \\
P_{6} & 0,1004 \\
P_{7} & 0,0638 \\
0,0450
\end{array}\right] w_{2}=\left[\begin{array}{l}
0,3304 \\
0,2059 \\
0,2574 \\
0,2063
\end{array}\right] w_{3}=\left[\begin{array}{l}
0,3285 \\
0,3579 \\
0,3137
\end{array}\right] w_{4}=\left[\begin{array}{l}
0,3726 \\
0,3556 \\
0,2718
\end{array}\right] w_{5}=\left[\begin{array}{l}
0,2355 \\
0,2443 \\
0,2765 \\
0,2437
\end{array}\right] w_{6}=\left[\begin{array}{l}
0,2686 \\
0,2331 \\
0,2531 \\
0,2552
\end{array}\right] w_{7}=\left[\begin{array}{l}
0,3939 \\
0,6061
\end{array}\right] w_{8}=\left[\begin{array}{l}
0,6154 \\
0,3846
\end{array}\right]
$$

Sonuç olarak her bir alt karar noktasının göreli önem değeri ile kendi karar noktasının değeri ile çarpılarak, önem değeri hesaplanmaktadır. Bu perspektifte nihai olarak elde edilen w sütun vektörü elde edilebilmektedir. Oluşturulan sütun vektörü beşinci adımda oluşturulan karar matrisine işlenmiştir.

\subsection{Adım-4: Tutarlılık Analizi}

10, 11, 12 ve 13. Eşitlikler kullanılarak, konfor ve ergonomi faktörü ile ilgili olarak kara vericilerin değerlendirmeleri için tutarlılık analizleri gerçekleştirilmiş ve bütün faktörler sirasiyla 0,$084 ; 0,063 ; 0,052 ; 0,035 ; 0,019 ; 0,001 ; 0,001$ puanlarını alarak tutarlı oldukları görülmüş̧ür. $\mathrm{Bu}$ adım tamamlandıktan sonra entropi yönteminin birinci, seçilen modelin beşinci adımına geçilmiştir.

\subsection{Adım-5: Karar Matrislerinin Oluşturulması}

Eşitlik 14 de gösterildiği gibi mxn boyutlu bir karar matrisi oluşturulmuştur. Karar matrisinin satır elemanları karar alternatiflerini gösterirken, sütün elemanları seçim kriterlerini ifade etmektedir.

\begin{tabular}{|c|c|c|c|c|c|c|c|c|c|c|c|}
\hline \multirow{3}{*}{$\begin{array}{r}106086 \\
68257 \\
69901\end{array}$} & 48 & 160000 & 33 & 6009500 & 6000 & 3 & 3500 & 36128000 & 38600 & 6,60 & 10700 \\
\hline & 48 & 110000 & 33 & 6009500 & 6000 & 1 & 2300 & 32426000 & 39500 & 6,70 & 9357 \\
\hline & 48 & 130000 & 33 & 6009500 & 6000 & 2 & 2500 & 36023800 & 45000 & 6,24 & 8990 \\
\hline 74836 & 48 & 150000 & 33 & 6009500 & 6000 & 3 & 2150 & 30219000 & 45000 & 6,24 & 8935 \\
\hline 58388 & 48 & 110000 & 30 & 6009500 & 6000 & 2 & 2100 & 39026000 & 44000 & 6,71 & 8107 \\
\hline 73191 & 48 & 140000 & 30 & 6009500 & 6000 & 3 & 2300 & 39026000 & 44000 & 6,86 & 9441 \\
\hline 51809 & 48 & 95000 & 30 & 3009500 & 6000 & 1 & 1020 & 21021000 & 28000 & 8,57 & 3464 \\
\hline 90461 & 48 & 113551 & 26 & 5706500 & 3500 & 3 & 2500 & 39526000 & 41000 & 6,86 & 9811 \\
\hline 87171 & 48 & 98622 & 27 & 2906500 & 3500 & 2 & 1100 & 20018000 & 44000 & 5,89 & 7510 \\
\hline 35526 & 48 & 57566 & 22 & 1206500 & 3500 & 1 & 750 & 1307500 & 16000 & 6,56 & 6474 \\
\hline 62171 & 48 & 106908 & 30 & 6009500 & 5500 & 3 & 2500 & 36810447 & 18000 & 5,92 & 7353 \\
\hline 50987 & 48 & 81414 & 30 & 6006500 & 3500 & 1 & 2150 & 30910099 & 18000 & 6,04 & 7901 \\
\hline 58388 & 48 & 87666 & 30 & 6006500 & 3500 & 2 & 2500 & 35310277 & 18000 & 6,04 & 7666 \\
\hline 58388 & 48 & 90188 & 30 & 5106500 & 3500 & 2 & 2500 & 35310268 & 18000 & 6,04 & 7675 \\
\hline 95724 & 48 & 185000 & 28 & 80013500 & 9000 & 3 & 2800 & 45021000 & 44000 & 6,23 & 9335 \\
\hline 92105 & 48 & 175000 & 28 & 80013500 & 9000 & 3 & 2100 & 30921000 & 44000 & 6,15 & 9890 \\
\hline 85855 & 48 & 120000 & 28 & 80013500 & 9000 & 1 & 1000 & 29022000 & 60000 & 6,50 & 6750 \\
\hline 88816 & 48 & 130000 & 28 & 80013500 & 9000 & 2 & 2500 & 33022000 & 40000 & 5,85 & 6355 \\
\hline 50658 & 48 & 90000 & 30 & 4008500 & 7000 & 2 & 1115 & 22818000 & 38000 & 4,66 & 13600 \\
\hline 76809 & 49 & 145000 & 30 & 4008500 & 7000 & 2 & 2000 & 33822000 & 44000 & 4,66 & 13000 \\
\hline 64803 & 36 & 85000 & 30 & 10006000 & 3000 & 3 & 2550 & 38219000 & 26000 & 5,72 & 8573 \\
\hline 41118 & 36 & 80000 & 30 & 6006000 & 3000 & 2 & 2550 & 27919000 & 26000 & 5,72 & 8131 \\
\hline
\end{tabular}




\subsection{Adım-6: Karar Matrislerinin Normalize Edilmesi}

Eşitlik 15 kullanılarak matris $\mathrm{X}$ in bütün elemanları normalize edilerek normalize matris $\mathrm{X}^{*}$ oluş̧urulmuştur.

$X^{*}=\left[\begin{array}{llllllllllll}0,069 & 0,046 & 0,063 & 0,0510,047 & 0,048 & 0,048 & 0,064 & 0,0750,051 & 0,066 & 0,050 & 0,048 & 0,057 \\ 0,044 & 0,046 & 0,043 & 0,0510,047 & 0,048 & 0,048 & 0,021 & 0,0490,046 & 0,061 & 0,051 & 0,049 & 0,050 \\ 0,045 & 0,046 & 0,051 & 0,0510,047 & 0,048 & 0,048 & 0,043 & 0,0540,051 & 0,056 & 0,058 & 0,046 & 0,048 \\ 0,049 & 0,046 & 0,059 & 0,0510,047 & 0,048 & 0,048 & 0,064 & 0,0460,043 & 0,045 & 0,058 & 0,046 & 0,047 \\ 0,038 & 0,046 & 0,043 & 0,0460,047 & 0,048 & 0,048 & 0,043 & 0,0450,055 & 0,061 & 0,056 & 0,049 & 0,043 \\ 0,047 & 0,046 & 0,055 & 0,0460,047 & 0,048 & 0,048 & 0,064 & 0,0490,055 & 0,061 & 0,056 & 0,050 & 0,050 \\ 0,034 & 0,046 & 0,037 & 0,0460,023 & 0,048 & 0,048 & 0,021 & 0,0220,030 & 0,049 & 0,036 & 0,063 & 0,018 \\ 0,059 & 0,046 & 0,045 & 0,0400,045 & 0,033 & 0,028 & 0,064 & 0,0540,056 & 0,061 & 0,053 & 0,050 & 0,052 \\ 0,057 & 0,046 & 0,039 & 0,0420,023 & 0,033 & 0,028 & 0,043 & 0,0240,028 & 0,042 & 0,056 & 0,043 & 0,040 \\ 0,023 & 0,046 & 0,023 & 0,0340,009 & 0,033 & 0,028 & 0,021 & 0,0160,018 & 0,018 & 0,021 & 0,048 & 0,034 \\ 0,040 & 0,046 & 0,042 & 0,0460,047 & 0,048 & 0,044 & 0,064 & 0,0540,052 & 0,025 & 0,023 & 0,043 & 0,039 \\ 0,033 & 0,046 & 0,032 & 0,0460,047 & 0,033 & 0,028 & 0,021 & 0,0460,044 & 0,024 & 0,023 & 0,044 & 0,042 \\ 0,038 & 0,046 & 0,035 & 0,0460,047 & 0,033 & 0,028 & 0,043 & 0,0540,050 & 0,024 & 0,023 & 0,044 & 0,041 \\ 0,038 & 0,046 & 0,035 & 0,0460,040 & 0,033 & 0,028 & 0,043 & 0,0540,050 & 0,024 & 0,023 & 0,044 & 0,041 \\ 0,062 & 0,046 & 0,073 & 0,0430,063 & 0,068 & 0,072 & 0,064 & 0,0600,064 & 0,049 & 0,056 & 0,046 & 0,049 \\ 0,060 & 0,046 & 0,069 & 0,0430,063 & 0,068 & 0,072 & 0,064 & 0,0450,044 & 0,049 & 0,056 & 0,045 & 0,052 \\ 0,056 & 0,046 & 0,047 & 0,0430,063 & 0,068 & 0,072 & 0,021 & 0,0220,041 & 0,052 & 0,077 & 0,048 & 0,036 \\ 0,058 & 0,046 & 0,051 & 0,0430,063 & 0,068 & 0,072 & 0,043 & 0,0540,047 & 0,052 & 0,051 & 0,043 & 0,034 \\ 0,033 & 0,046 & 0,035 & 0,0460,031 & 0,043 & 0,056 & 0,043 & 0,0240,032 & 0,042 & 0,049 & 0,034 & 0,072 \\ 0,050 & 0,047 & 0,057 & 0,0460,031 & 0,043 & 0,056 & 0,043 & 0,0430,048 & 0,052 & 0,056 & 0,034 & 0,069 \\ 0,042 & 0,035 & 0,033 & 0,0460,078 & 0,030 & 0,024 & 0,064 & 0,0550,054 & 0,045 & 0,033 & 0,042 & 0,045 \\ 0,027 & 0,035 & 0,031 & 0,0460,047 & 0,030 & 0,024 & 0,043 & 0,0550,040 & 0,045 & 0,033 & 0,042 & 0,043\end{array}\right]$

\subsection{Adım-7: Faktörlere İlişkin Entropi Değerinin Hesaplanması}

$\mathrm{Bu}$ adımda eşitlik 17 kullanılarak normalize matrisin elemanları için entropi değeri hesaplanmış, ardından elemanlar için entropi değerini gösteren matris E elde edilmiştir. Her bir faktör için entropi değeri eşitlik 19 yardımıyla hesaplanırken, eşitlik 20 kullanılarak faktörlerin belirsizlik değeri belirlenmiştir.

\begin{tabular}{|c|c|c|c|c|c|c|c|c|c|c|c|c|}
\hline$P 11$ & $-0,1842$ & $-0,1426$ & $-0,1741$ & $-0,1515$ & $-0,1435$ & $-0,1457-0,1461$ & $-0,1756$ & $-0,1947$ & $-0,1522-0,1788$ & $-0,1489$ & $-0,1463$ & $-0,1626$ \\
\hline$P 12$ & $-0,1380$ & $-0,1426$ & $-0,1359$ & $-0,1515$ & $-0,1435$ & $-0,1457-0,1461$ & $-0,0819$ & $-0,1487$ & $-0,1415-0,1706$ & $-0,1512$ & $-0,1478$ & $-0,1488$ \\
\hline$P 13$ & $-0,1403$ & $-0,1426$ & $-0,1521$ & $-0,1515$ & $-0,1435$ & $-0,1457-0,1461$ & $-0,1343$ & $-0,1572$ & $-0,1519-0,1611$ & $-0,1647$ & $-0,1409$ & $-0,1449$ \\
\hline$P 14$ & $-0,1469$ & $-0,1426$ & $-0,1670$ & $-0,1515$ & $-0,1435$ & $-0,1457-0,1461$ & $-0,1756$ & $-0,1422$ & $-0,1349-0,1386$ & $-0,1647$ & $-0,1409$ & \\
\hline$P 21$ & $-0,1240$ & $-0,1426$ & $-0,1359$ & $-0,1421$ & $-0,1435$ & $-0,1457-0,1461$ & $-0,1343$ & $-0,1399$ & $01-0,1706$ & $-0,1623$ & & \\
\hline$P 22$ & $-0,1447$ & $-0,1426$ & $-0,1597$ & $-0,1421$ & $-0,1435$ & $-0,1457-0,1461$ & $-0,1756$ & $-0,1487$ & $-0,1601-0,1706$ & $-0,1623$ & 1501 & \\
\hline$P 23$ & $-0,1140$ & $-0,1426$ & $-0,1229$ & $-0,1421$ & $-0,0880$ & $-0,1457-0,1461$ & $-0,0819$ & $-0,0838$ & $-0,1047-0,1483$ & 195 & 736 & \\
\hline P31 & $-0,1664$ & $-0,1426$ & $-0,1389$ & $-0,1289$ & $-0,1386$ & $-0,1122-0,1004$ & $-0,1756$ & $-0,1572$ & $-0,1615-0,1706$ & $-0,1550$ & & \\
\hline P32 & $-0,1624$ & $-0,1426$ & $-0,1261$ & $-0,1323$ & $-0,0859$ & $-0,1122-0,1004$ & & $-0,0886$ & $-0,1011-0,1336$ & 623 & & \\
\hline P33 & $-0,0869$ & $-0,1426$ & $-0,0858$ & $-0,1147$ & $-0,0438$ & $-0,1122-0,1004$ & $-0,0819$ & $-0,0666$ & $-0,0736-0,0711$ & $-0,0798$ & $-0,1457$ & \\
\hline$P 41$ & $-0,1295$ & $-0,1426$ & $-0,1333$ & $-0,1421$ & $-0,1435$ & $-0,1457-0,1378$ & $-0,1756$ & $-0,1572$ & $-0,1541-0,0909$ & $-0,0870$ & $-0,1359$ & $-0,1263$ \\
\hline$P 42$ & $-0,1128$ & $-0,1426$ & $-0,1102$ & $-0,1421$ & $-0,1435$ & $-0,1122-0,1004$ & $-0,0819$ & $-0,1422$ & $-0,1370-0,0887$ & $-0,0870$ & $-0,1378$ & 1327 \\
\hline$P 43$ & $-0,1240$ & $-0,1426$ & $-0,1162$ & $-0,1421$ & $-0,1435$ & $-0,1122-0,1004$ & $-0,1343$ & $-0,1572$ & $-0,1499-0,0898$ & $-0,0870$ & & $-0,1300$ \\
\hline$P 44$ & $-0,1240$ & $-0,1426$ & $-0,1185$ & $-0,1421$ & $-0,1285$ & $-0,1122-0,1004$ & $-0,1343$ & $-0,1572$ & $-0,1499-0,0897$ & $-0,0870$ & $-0,1378$ & $-0,1301$ \\
\hline P51 & $-0,1726$ & $-0,1426$ & $-0,1908$ & $-0,1356$ & $-0,1734$ & $-0,1831-0,1899$ & $-0,1756$ & $-0,1692$ & $-0,1756-0,1483$ & 623 & $-0,1406$ & \\
\hline P52 & $-0,1684$ & $-0,1426$ & $-0,1843$ & $-0,1356$ & $-0,1734$ & $-0,1831-0,1899$ & $-0,1756$ & $-0,1399$ & $-0,1371-0,1483$ & $-0,1623$ & $-0,1394$ & \\
\hline P53 & $-0,1608$ & $-0,1426$ & $-0,1442$ & $-0,1356$ & $-0,1734$ & $-0,1831-0,1899$ & $-0,0819$ & $-0,0826$ & $-0,1312-0,1529$ & $-0,1974$ & $-0,1448$ & $-0,1190$ \\
\hline P54 & $-0,1644$ & $-0,1426$ & $-0,1521$ & $-0,1356$ & $-0,1734$ & $-0,1831-0,1899$ & $-0,1343$ & $-0,1572$ & $-0,1433-0,1529$ & $-0,1524$ & $-0,1348$ & $-0,1141$ \\
\hline$P 61$ & $-0,1122$ & $-0,1426$ & $-0,1183$ & $-0,1421$ & $-0,1084$ & $-0,1352-0,1618$ & $-0,1343$ & $-0,0895$ & $-0,1110-0,1336$ & $-0,1473$ & $-0,1152$ & $-0,1894$ \\
\hline$P 62$ & $-0,1494$ & $-0,1446$ & $-0,1634$ & $-0,1421$ & $-0,1084$ & $-0,1352-0,1618$ & $-0,1343$ & $-0,1354$ & $-0,1456-0,1529$ & $-0,1623$ & $-0,1152$ & $-0,1841$ \\
\hline$P 71$ & $-0,1332$ & $-0,1170$ & $-0,1137$ & $-0,1421$ & $-0,1993$ & $-0,1060-0,0898$ & $-0,1756$ & $-0,1593$ & $-0,1580-0,1386$ & $-0,1135$ & $-0,1328$ & $-0,1403$ \\
\hline$P 72$ & $-0,0967$ & $-0,1170$ & $-0,1089$ & $-0,1421$ & $-0,1435$ & $-0,1060-0,0898$ & $-0,1343$ & $-0,1593$ & $-0,1278-0,1386$ & $-0,1135$ & $-0,1328$ & $-0,1353$ \\
\hline$e j$ & 0,9886 & 0,9990 & 0,9875 & 0,9988 & 0,9801 & $0,9878 \quad 0,9790$ & 0,9782 & 0,9814 & $0,9906 \quad 0,9832$ & 0,9802 & 0,9976 & 0,9899 \\
\hline$d j$ & 0,0114 & 0,0010 & 0,0125 & 0,0012 & 0,0199 & $0,0122 \quad 0,0210$ & 0,0218 & 0,0186 & $0,0094 \quad 0,0168$ & 0,0198 & 0,0024 & 0,0101 \\
\hline
\end{tabular}




\subsection{Adım-8: Faktörlerin Ağırlık Değerlerinin Hesaplanması}

Her bir faktör için hesaplanan belirsizlik değeri belirsizlik değerinin toplamına bölünerek faktörlerin ağırlık değerleri belirlenmektedir.

$$
w=\left[\begin{array}{cccccccccccccc}
C 1 & C 2 & C 3 & C 4 & C 5 & C 6 & C 7 & C 8 & C 9 & C 10 & C 11 & C 12 & C 13 & C 14 \\
0,064 & 0,005 & 0,071 & 0,007 & 0,112 & 0,069 & 0,118 & 0,122 & 0,104 & 0,053 & 0,094 & 0,111 & 0,014 & 0,056
\end{array}\right]
$$

Bütün faktörlerin göreli ağırlık değerleri entropi yönetimine göre hesaplandıktan sonra, bir sonraki adıma geçilmiş, bütün karar noktalarının göreli önem değerleri TOPSIS yönteminin uygulama adımları izlenerek hesaplanmıştır.

\subsection{Adım-9: Karar Matrislerinin Oluşturulması}

Entropi yönetimin kullanıldığı beşinci adımdaki karar matrisi X aynı şekilde alınmıştır.

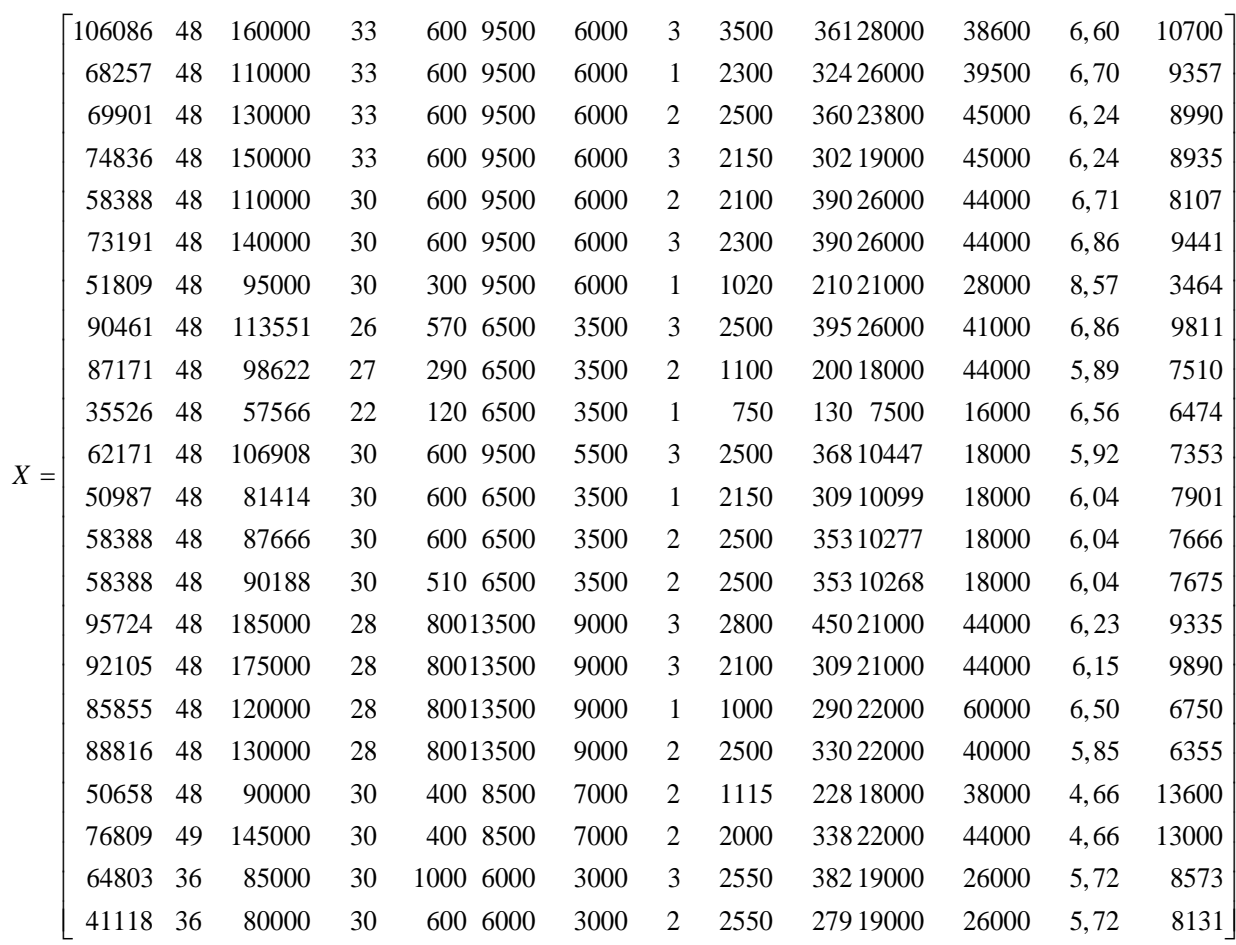




\subsection{Adım-10: Karar Matrislerinin Normalize Edilmesi}

Eşitlik 22 kullanılarak karar matrisinin tüm elemanları normalize edilmiş ve normalize matris R oluşturulmuştur.

\begin{tabular}{|c|c|c|c|c|c|c|c|c|c|c|c|c|}
\hline 0,312 & 0,217 & 0,284 & 0,238 & 0,209 & 0,217 & 0,213 & 0,456 & $0,3360,234$ & 0,295 & 0,220 & 0,225 & \\
\hline 0,201 & 0,217 & 0,196 & 0,238 & 0,209 & 0,217 & 0,213 & 0,285 & $0,2210,210$ & 0,273 & 0,225 & 0,228 & 0,225 \\
\hline 0,206 & 0,217 & 0,231 & 0,238 & 0,209 & 0,217 & 0,213 & 0,356 & $0,2400,233$ & 0,250 & 0,257 & 0,212 & 0,217 \\
\hline 0,220 & 0,217 & 0,267 & 0,238 & 0,209 & 0,217 & 0,213 & 0,285 & $0,2070,196$ & 0,200 & 0,257 & 0,212 & 0,215 \\
\hline 0,172 & 0,217 & 0,196 & 0,216 & 0,209 & 0,217 & 0,213 & 0,241 & $0,2020,253$ & 0,273 & 0,251 & 0,228 & 0,195 \\
\hline 0,215 & 0,217 & 0,249 & 0,216 & 0,209 & 0,217 & 0,213 & 0,262 & $0,2210,253$ & 0,273 & 0,251 & 0,234 & 0,227 \\
\hline 0,152 & 0,217 & 0,169 & 0,216 & 0,104 & 0,217 & 0,213 & 0,230 & $0,0980,136$ & 0,221 & 0,160 & 0,292 & 0,083 \\
\hline 0,266 & 0,217 & 0,202 & 0,187 & 0,198 & 0,148 & 0,124 & 0,299 & $0,2400,256$ & 0,273 & 0,234 & 0,234 & 0,236 \\
\hline 0,257 & 0,217 & 0,175 & 0,194 & 0,101 & 0,148 & 0,124 & 0,285 & $0,1060,130$ & 0,189 & 0,251 & 0,200 & 0,181 \\
\hline 0,105 & 0,217 & 0,102 & 0,158 & 0,042 & 0,148 & 0,124 & 0,218 & $0,0720,084$ & 0,079 & 0,091 & 0,223 & 0,156 \\
\hline 0,183 & 0,217 & 0,190 & 0,216 & 0,209 & 0,217 & 0,195 & 0,063 & $0,2400,239$ & 0,110 & 0,103 & 0,202 & 0,177 \\
\hline 0,150 & 0,217 & 0,145 & 0,216 & 0,209 & 0,148 & 0,124 & 0,065 & $0,2070,200$ & 0,106 & 0,103 & 0,206 & 0,190 \\
\hline 0,172 & 0,217 & 0,156 & 0,216 & 0,209 & 0,148 & 0,124 & 0,074 & $0,2400,229$ & 0,108 & 0,103 & 0,206 & 0,185 \\
\hline 0,172 & 0,217 & 0,160 & 0,216 & 0,178 & 0,148 & 0,124 & 0,065 & $0,2400,229$ & 0,108 & 0,103 & 0,206 & 0,185 \\
\hline 0,282 & 0,217 & 0,329 & 0,202 & 0,278 & 0,308 & 0,319 & 0,072 & $0,2690,292$ & 0,221 & 0,251 & 0,212 & 0,225 \\
\hline 0,271 & 0,217 & 0,311 & 0,202 & 0,278 & 0,308 & 0,319 & 0,062 & $0,2020,200$ & 0,221 & 0,251 & 0,209 & 0,238 \\
\hline 0,253 & 0,217 & 0,213 & 0,202 & 0,278 & 0,308 & 0,319 & 0,068 & $0,0960,188$ & 0,231 & 0,342 & 0,221 & 0,163 \\
\hline 0,261 & 0,217 & 0,231 & 0,202 & 0,278 & 0,308 & 0,319 & 0,068 & $0,2400,214$ & 0,231 & 0,228 & 0,199 & 0,153 \\
\hline 0,149 & 0,217 & 0,160 & 0,216 & 0,139 & 0,194 & 0,248 & 0,101 & $0,1070,148$ & 0,189 & 0,217 & 0,159 & 0,328 \\
\hline 0,226 & 0,222 & 0,258 & 0,216 & 0,139 & 0,194 & 0,248 & 0,156 & $0,1920,219$ & 0,231 & 0,251 & 0,159 & 0,313 \\
\hline 0,191 & 0,163 & 0,151 & 0,216 & 0,348 & 0,137 & 0,106 & 0,158 & $0,2450,248$ & 0,200 & 0,148 & 0,195 & 0,207 \\
\hline 0,121 & 0,163 & 0,142 & 0,216 & 0,209 & 0,137 & 0,106 & 0,099 & $0,2450,181$ & 0,200 & 0,148 & 0,195 & 0,196 \\
\hline
\end{tabular}

\subsection{Adım-11: Normalize Matrisin Ăğırıklandırılması}

R matrisinin her bir elamanı kendi sütunu için belirlenmiş ağırlık değeri ile çarpılarak ağırlıklandırılmış normalize matris $\mathrm{V}$ oluş̧turulmuştur. Faktörlerin ağırlık değerleri sekizinci adımda hesaplanmış ve sütun vektörü w ile gösterilmiştir.

\footnotetext{
$\left[\begin{array}{lllllllllllllll}0,01996 & 0,00116 & 0,02005 & 0,00158 & 0,02335 & 0,01488 & 0,02510 & 0,05589 & 0,03508 & 0,01232 & 0,02783 & 0,02447 & 0,00308 & 0,01456\end{array}\right]$ $\begin{array}{llllllllllllllll}0,01284 & 0,00116 & 0,01378 & 0,00158 & 0,02335 & 0,01488 & 0,02510 & 0,03484 & 0,02305 & 0,01106 & 0,02584 & 0,02504 & 0,00312 & 0,01273\end{array}$ $\begin{array}{llllllllllllll}0,01315 & 0,00116 & 0,01629 & 0,00158 & 0,02335 & 0,01488 & 0,02510 & 0,04354 & 0,02506 & 0,01228 & 0,02365 & 0,02852 & 0,00291 & 0,01223\end{array}$

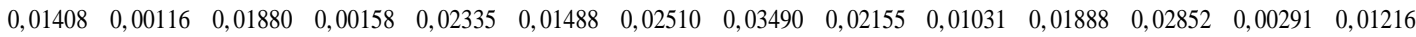
$\begin{array}{lllllllllllllll}0,01099 & 0,00116 & 0,01378 & 0,00144 & 0,02335 & 0,01488 & 0,02510 & 0,02947 & 0,02105 & 0,01331 & 0,02584 & 0,02789 & 0,00313 & 0,01103\end{array}$

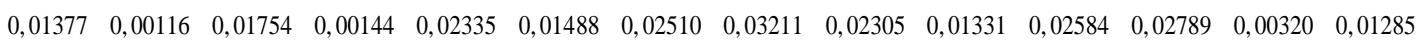

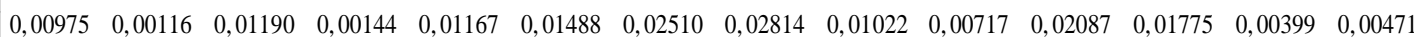
$\begin{array}{lllllllllllllll}0,01702 & 0,00116 & 0,01423 & 0,00124 & 0,02218 & 0,01018 & 0,01464 & 0,03657 & 0,02506 & 0,01348 & 0,02584 & 0,02599 & 0,00320 & 0,01335\end{array}$ $\begin{array}{lllllllllllllll}0,01640 & 0,00116 & 0,01236 & 0,00129 & 0,01129 & 0,01018 & 0,01464 & 0,03490 & 0,01103 & 0,00682 & 0,01789 & 0,02789 & 0,00275 & 0,01022\end{array}$ $\begin{array}{llllllllllllll}0,00668 & 0,00116 & 0,00721 & 0,00105 & 0,00467 & 0,01018 & 0,01464 & 0,02667 & 0,00752 & 0,00444 & 0,00745 & 0,01014 & 0,00306 & 0,00881\end{array}$ $\begin{array}{llllllllllllll}0,01170 & 0,00116 & 0,01340 & 0,00144 & 0,02335 & 0,01488 & 0,02301 & 0,00771 & 0,02506 & 0,01256 & 0,01038 & 0,01141 & 0,00276 & 0,01001\end{array}$ $\begin{array}{lllllllllllllll}0,00959 & 0,00116 & 0,01020 & 0,00144 & 0,02335 & 0,01018 & 0,01464 & 0,00799 & 0,02155 & 0,01054 & 0,01004 & 0,01141 & 0,00282 & 0,01075\end{array}$ $\begin{array}{llllllllllllll}0,01099 & 0,00116 & 0,01099 & 0,00144 & 0,02335 & 0,01018 & 0,01464 & 0,00905 & 0,02506 & 0,01205 & 0,01021 & 0,01141 & 0,00282 & 0,01043\end{array}$ $\begin{array}{lllllllllllllll}0,01099 & 0,00116 & 0,01130 & 0,00144 & 0,01985 & 0,01018 & 0,01464 & 0,00798 & 0,02506 & 0,01205 & 0,01020 & 0,01141 & 0,00282 & 0,01044\end{array}$

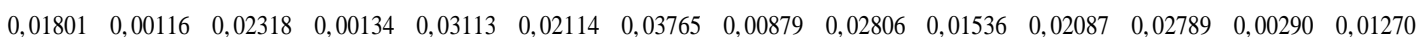
$\begin{array}{llllllllllllllll}0,01733 & 0,00116 & 0,02193 & 0,00134 & 0,03113 & 0,02114 & 0,03765 & 0,00763 & 0,02105 & 0,01054 & 0,02087 & 0,02789 & 0,00286 & 0,01346\end{array}$ $\begin{array}{llllllllllllllll}0,01615 & 0,00116 & 0,01504 & 0,00134 & 0,03113 & 0,02114 & 0,03765 & 0,00828 & 0,01002 & 0,00990 & 0,02186 & 0,03803 & 0,00303 & 0,00919\end{array}$ $\begin{array}{lllllllllllllll}0,01671 & 0,00116 & 0,01629 & 0,00134 & 0,03113 & 0,02114 & 0,03765 & 0,00835 & 0,02506 & 0,01126 & 0,02186 & 0,02535 & 0,00273 & 0,00865\end{array}$

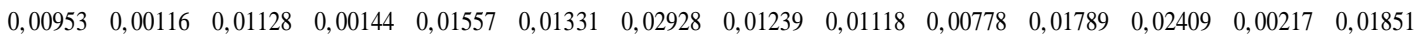
$\begin{array}{lllllllllllllll}0,01445 & 0,00119 & 0,01817 & 0,00144 & 0,01557 & 0,01331 & 0,02928 & 0,01906 & 0,02005 & 0,01153 & 0,02186 & 0,02789 & 0,00217 & 0,01769\end{array}$ $\begin{array}{llllllllllllll}0,01219 & 0,00087 & 0,01065 & 0,00144 & 0,03891 & 0,00940 & 0,01255 & 0,01936 & 0,02556 & 0,01304 & 0,01888 & 0,01648 & 0,00267 & 0,01167\end{array}$ $\left[\begin{array}{llllllllllllll}0,00774 & 0,00087 & 0,01002 & 0,00144 & 0,02335 & 0,00940 & 0,01255 & 0,01210 & 0,02556 & 0,00952 & 0,01888 & 0,01648 & 0,00267 & 0,01107\end{array}\right]$
} 


\subsection{Adım-12: İdeal ve Negatif İdeal Çözüm Değerlerinin Hesaplanması}

Eşitlik 25 ve 26 kullanılarak maksimum ve minimum yönlü faktörler için ideal ve negatif ideal değerleri hesaplanmıştır. İdeal çözüm kümesi A* ile gösterilirken, negatif ideal çözüm kümesi $\mathrm{A}^{-}$ile gösterilmektedir.

\begin{tabular}{|c|c|c|c|c|c|c|c|c|c|}
\hline \multirow{2}{*}{$A^{*}=$} & $\{0,0200$ & 0,0012 & 0,0072 & 0,0011 & 0,0389 & 0,0094 & 0,0125 & 0,0559 & 0,0351 \\
\hline & 0,0154 & 0,0278 & 0,0380 & 0,0040 & 0,0185 & & & & \\
\hline \multirow[t]{2}{*}{$4^{-}=\{$} & & 0,0009 & 0,0232 & 0,0016 & 0,0047 & 0,0211 & 0,0376 & 0,0076 & 0,0075 \\
\hline & 8044 & 0,0075 & 0,0101 & 0,0022 & 0,0047 & & & & \\
\hline
\end{tabular}

\subsection{Adım-13: Ayırım Ölçülerinin Hesaplanması}

Eşitlik 27 ve 28 kullanılarak ayrım ölçütleri hesaplanmış, eşitlik 27 yardımıyla bütün karar noktaları için ideal çözüm perspektifinde ayrım ölçütleri hesaplanırken, elde edilen değerler ile ideal ayrım ölçütleri için matris L* oluşturulmuştur.

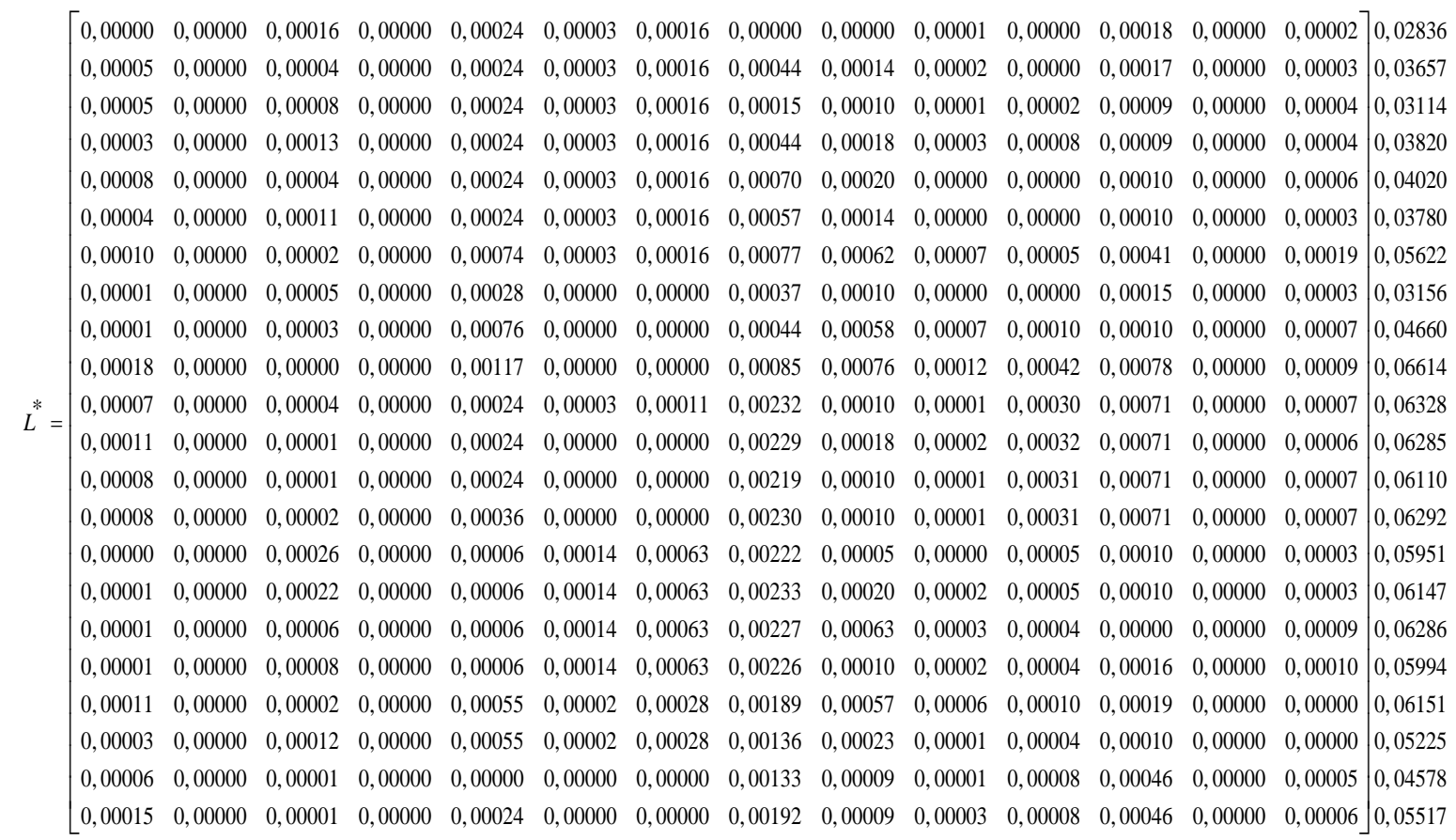
edilmiştir.

Ardından eşitlik 28 kullanılarak negatif ideal ayrım ölçütlerini gösteren matris L' elde 


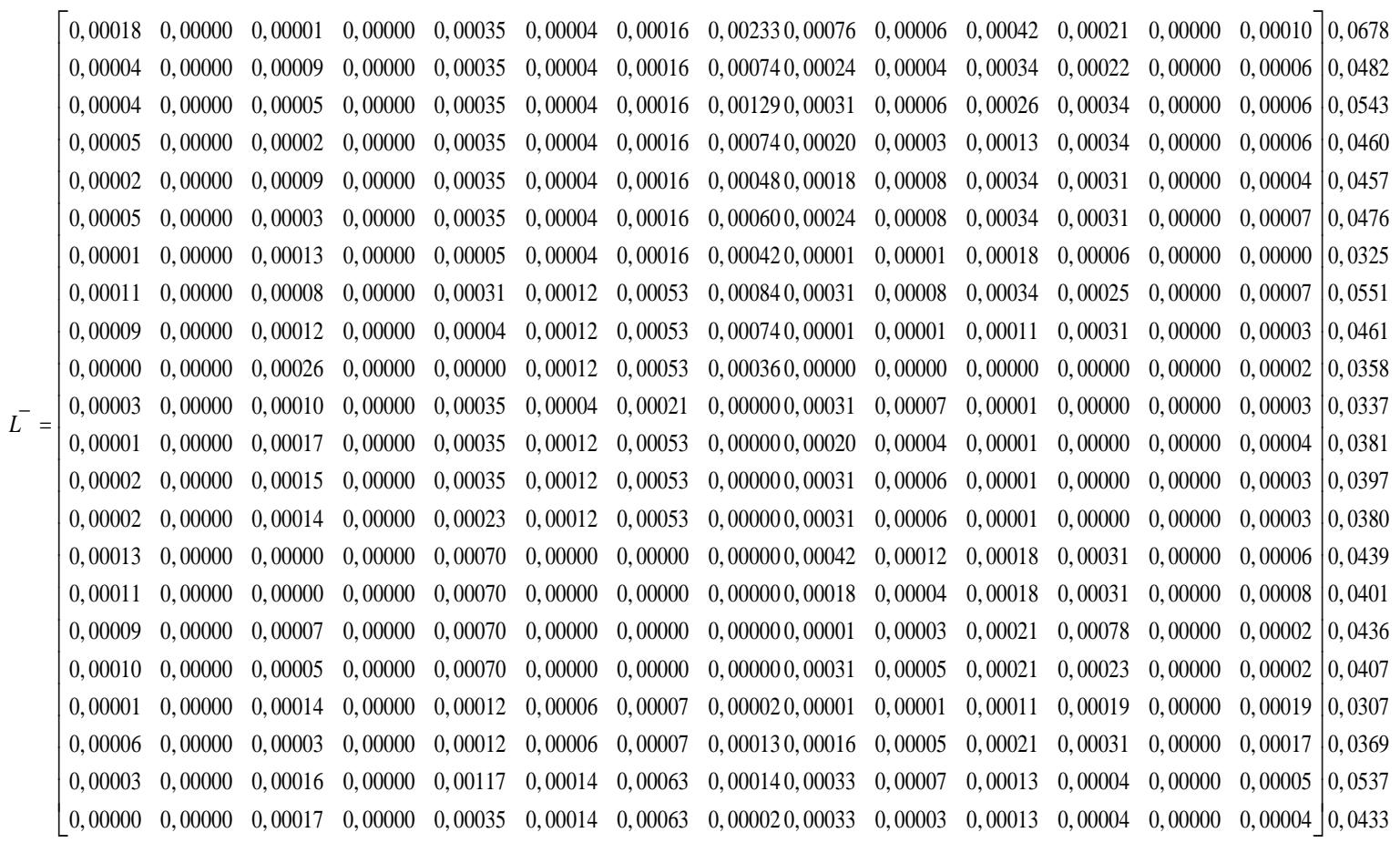

\subsection{Adım-14: İdeal Çözüme Göreli Yakınlığın Hesaplanması}

Eşitlik 29 kullanılarak her bir karar noktası için ideal çözüme yakınlık hesaplanmış, elde edilen değerler çerçevesinde bütün karar noktaları aldıkları skorlara göre sıralandırılmıştır. 
Tablo 3.Karar alternatiflerinin aldıkları skorlar ve siralama

\begin{tabular}{clcc}
\hline Marka & \multicolumn{1}{c}{ Model } & \multicolumn{1}{c}{ Skor } & Siralama \\
\hline \multirow{4}{*}{ Marka-S } & S Serisi & 0,7051329693 & 1 \\
& P Serisi & 0,5685803447 & 4 \\
& G Serisi & 0,6356616468 & 3 \\
& R Serisi & 0,5464905545 & 6 \\
& CF & 0,5318031368 & 8 \\
Marka-D & XF & 0,5574701978 & 5 \\
& LF & 0,3666345148 & 19 \\
& Actros & 0,6357680635 & 2 \\
Marka-M & Arocs & 0,4970645921 & 9 \\
& Atego & 0,3514936246 & 20 \\
& F-MAX & 0,3474796129 & 21 \\
& 1842T & 0,3776627953 & 17 \\
& 1848T & 0,3938195588 & 16 \\
& 1848 T M & 0,3768452567 & 18 \\
& FH-16 & 0,4247698239 & 11 \\
Marka-V & FH & 0,3947610014 & 15 \\
& FMX & 0,4094234851 & 13 \\
& FM & 0,4045072644 & 14 \\
Marka-I & STRALIS AS & 0,3327507137 & 22 \\
& STRALIS NP & 0,4141979173 & 12 \\
Marka-R & T440 & 0,5398288479 & 7 \\
& T380 & 0,4396519887 & 10 \\
\hline
\end{tabular}

\section{Sonuç ve Değerlendirme}

Seçilen hibrid model kullanılarak yapılan analizde en yüksek değeri alan Marka-S'nin S serisi olarak tanımladığı model en iyi ve en uygun karar alternatifi olarak belirlenmiştir. En iyi ikinci alternatif dahil olmak üzere söz konusu modelin aldığı değer ile diğerleri arasında kayda değer bir fark göze çarpmaktadır.

Şekil 4. Karar alternatiflerinin sıralanması

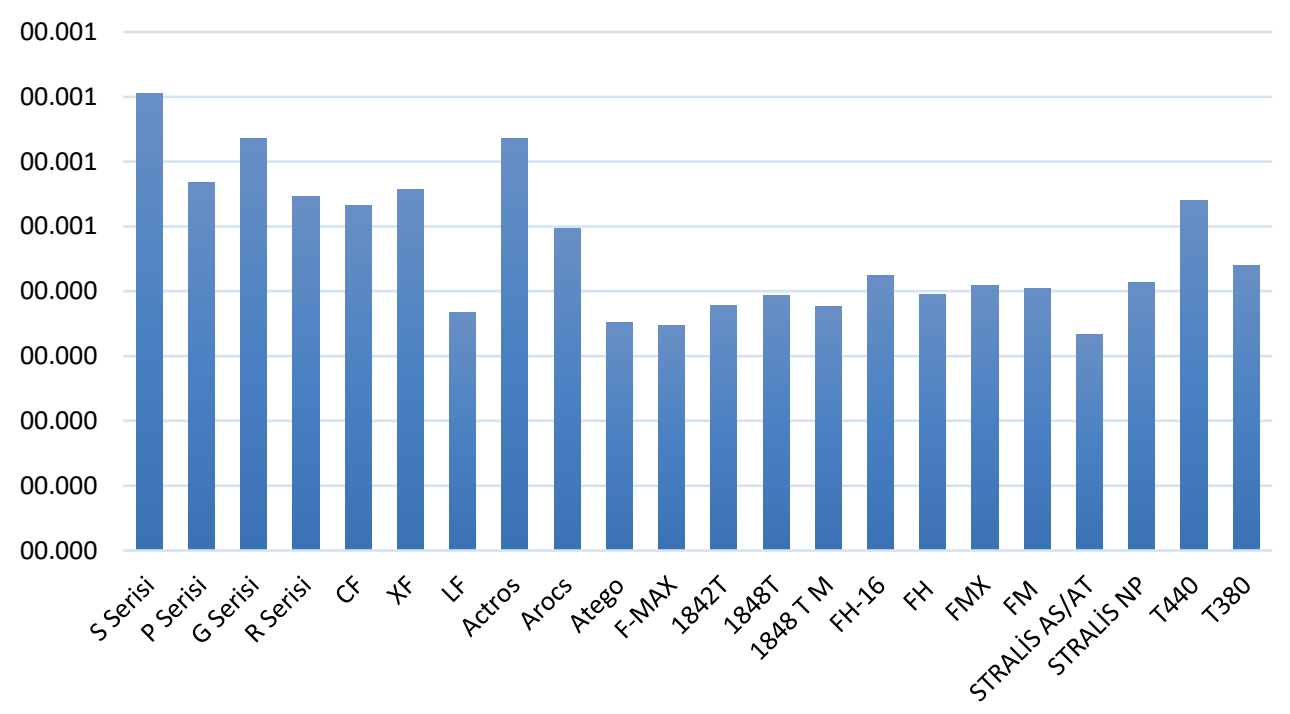


Minimizasyon yönlü faktörler çerçevesinde Marka-S'nin S serisi olarak tanımlanan modeli özellikle aracın satın alma fiyatı ile bakım maliyeti gibi kriterler dikkate alındığında en yüksek değere sahipken, diğer faktörler açısından rakiplerinden daha iyi skorlar almamıştır. Buna karşıllk, maksimum yönlü faktörler açısından rakiplerine kıyasla oldukça yüksek değerler aldığ1 görülebilmektedir. Dolayısıyla söz konusu modelin en iyi alternatif olması minimize olması beklenen faktörlerde en iyi skorları elde etmekten çok, maksimize olması beklenen faktörlerde en iyi değerleri almasından kaynaklanmaktadır.

Aynı zamanda en iyi ve en kötü alternatifler arasında oluşan skor farkı yaklaşık üç katı olarak gerçekleşmiş, en kötü skora sahip alternatif en iyi skora sahip alternatifin yaklaşık olarak \%30 unun biraz üzerinde değer almıştır. Bu açıdan bakıldığında en iyi alternatif ile en kötü alternatif arasında kayda değer bir fark göze çarpmaktadır.

Markalar çerçevesinde değerlendirme yapıldığı zaman aldıkları sonuçlar çerçevesinde en iyi alternatifin de yer aldığı Marka-S'nin modelleri birbirine yakın skorlar alarak birincilikle altıncılık arasında sıralanmışlardır. Buna karşılık diğer Markalara ait modellerin sıralanması açısından dikkate değer bir dalgalanma görülebilmektedir. Örnek olarak Marka-M'nin ürettiği modeller ikinci, dokuzuncu ve yirminci en iyi alternatif olabilmişler, benzer bir biçimde MarkaD'nin modelleri beşinci, sekizinci ve on dokuzuncu alternatifler olabilmişlerdir. Bunun yanı sıra alt sıralarda yer alsalar da diğer Markaların ürettikleri modellerin sıralamadaki yerleri büyük oranda ardışıktır.

Faktörler çerçevesinde sonuçlar değerlendirildiğinde ergonomi ve konfor olarak tanımlanan faktör \%12,2 önem değeri ile en önemli faktör konumundadır. Bu açıdan bakıldığında 0,1134 değeri ile en iyi alternatif olarak belirlenen modelin en yüksek değeri aldığı, ikinci olan Marka-M'nin Actros modelinin ise 0,0742 ile en iyi üçüncü değere sahip alternatif olduğu görülmektedir. Ek olarak en iyi alternatif olma açısından ilk üç içerisinde yer alan modellerin ergonomi ve konfor açısından da en yüksek değerleri alan alternatifler oldukları göze çarpmaktadır.

İkinci en yüksek önem değerine sahip seçim kriteri olan yedek parça ve servis maliyeti faktörü açısından dağılım son derece değişkendir. En iyi alternatiflerin bu faktör açısından en iyi skorları almadıkları, buna karşılık sıralamada en altlarda yer alan modellerin bu konuda oldukça iyi skorlar aldıkları göze çarpmaktadır. Üçüncü önemli seçim kriteri olan yakıt deposu büyüklüğü sonuca çok fazla etki etmemektedir. Bunun temel nedeni karar noktaları açısından yakıt deposu büyüklüklerinin birbirine son derece yakın olması aralarında büyük bir farkın bulunmamasıdır. Yüksek tork gücü açısında S serisi modeli hariç sıralama ile ilişkili bir dağılım göze çarpmazken, aynı şekilde yüklü katar ağırlı̆̆ 1 faktörünün de sıralamayı önemli ölçüde etkilemediği söylenebilmektedir.

Sonuç olarak değerlendirildiğinde modellere ilişkin sıralamada ergonomi ve konfor faktörüne ek olarak teknik bazı faktörlerin etkilerinin yüksek olduğu tespit edilebilmektedir. Bu açıdan çekici araç üreten işletmelerin bu faktörlere odaklanmaları ürettikleri modellerin daha yüksek düzeyde tercih edilebilir modeller olmasına olanak sağlayabilir. Öte yandan aracın satın alma fiyatı ve ikinci el satın alma değeri gibi faktörlerin tercih edilebilirlik açısından teknik özelliklerden daha önemli olmadığı görülebilmektedir. Dolayısıyla uluslararası karayolu taşımacılığında yer alan taşımacılık işletmelerine daha etkin bir biçimde ürün arz edebilmek için fiyatlara ilişkin düzenlemeler, indirim ve kampanyalar gibi finansal enstrümanların kullanılması üretici işletmeler için vazgeçilmez bir öncelik olarak değerlendirilmemelidir. Üretici işletmelerin modellerini teknik açıdan geliştirmesi durumunda tercih edilebilirlikleri önemli ölçüde artış gösterebilir. 


\section{Kaynakça}

Aalami, H.A., Moghaddam, M. P. veYousefi, G.R. (2010). Modeling and prioritizing demand response programs in power markets, Electric Power Systems Research, 80: 426-435.

Akyene, T. (2012). Cell phone evaluation base on entropy and TOPSIS, Interdisciplinary Journal of Research in Business, 1 (12): 09-15.

Bo, D. (2010). Analysis of external environment of transmission project based on improved Entropy TOPSIS method, Water Resources and Power, 2: 37-45.

Chauhan. R., Singh, T., Tiwari, A., Patnaik, A. ve Thakur, N. S. (2017). Hybrid entropyTOPSIS approach for energy performance prioritization in a rectangular channel employing impinging air jets, Energy, 134: 360-368.

Chen, F., Wang, J. ve Deng, Y. (2015). Road safety risk evaluation by means of improved entropy TOPSIS-RSR, Safety Science, 79: 39-54.

Chen, W., Meng, D. ve He, Z. (2011). Comprehensive evaluation and spatial pattern of regional urbanization level in Henan, Progress in Geography, 30: 978-985.

Cheng, Y., Ren, J., Cu1, H. ve Tang G. (2012). a research using ENTROPY-TOPSIS method on regional development modes in perspective of the three-dimensional framework: a case study of Shandong province, Economic Geography,6: 57-66.

Deepa R. ve Swamynathan, S. (2015). AHP-Entropy-TOPSIS based clustering protocol for mobile ad hoc networks, Ad Hoc Sensors and Wireless Network, 24 (1/2): 161-177.

Freeman, J. ve Chen, T. (2015). Green supplier selection using an AHP-Entropy-TOPSIS framework, Supply Chain Management: An International Journal, 20 (3): 327-340.

Gao, L. ve Xi, Y. (2012). The evaluation study of the industry technological innovation capability in Fujian province based on the Entropy TOPSIS, Science Technology and Industry, 6: 136-144.

Hong-yan, C. (2004). Improved technique for order preference by similarity to ideal solution and its application in bid-evaluating of construction project, Systems Engineering-Theory Methodology Application, 13 (5): 471-473.

Hsu, P.F. ve Hsu M.G. (2008). Optimizing the information outsourcing practices of primary care medical organizations using entropy and TOPSIS, Quality and Quantity, 42 (2): 181201

Huang, J. (2008). Combining entropy weight and TOPSIS method for information system selection. In Proceedings of the IEEE conference on cybernetics and intelligent systems, CIS 2008, 1281-1284.

Jozi S. A., Shafiee, M., MoradiMajd, N. ve Saffarian, S. (2012). An integrated Shannon's Entropy-TOPSIS methodology for environmental risk assessment of Helleh protected area in Iran, Environmental Monitoring and Assessment, 184 (11): 6913-6922.

Li, X., Wang, K., Liu, L., Xin, J., Yang, H. ve Gao C (2011). Application of the entropy weight and TOPSIS method in safety evaluation of coal mines, Procedia Engineering, 26: 20852091.

Li-juan, M. (2002). Supply chain management-based supplier selection: A tentative exploration, Industrial Engineering and Management, 7 (6): 23-25.

Meng, X.M. ve Hu, H.P. (2009). Application of set pair analysis model based on entropy weight to comprehensive evaluation of water quality, Journal of Hydraulic Engineering, 3: 257-262. 
Nie, L., ve Dong, G. (2010). A study on competitiveness of cruise tourism in port cities based on entropy-TOPSIS, Tourism Forum, 3: 789-794.

Ouyang, L.Y., Chen, K. S., Yang, C. M., ve Hsu, C. H. (2014). Using a QCAC-EntropyTOPSIS approach to measure quality characteristics and rank improvement priorities for all substandard quality characteristics, International Journal of Production Research, 52 (10): 3110-3124.

Pan L., Yi, Q. ve Ge, L. T. (2004). Comprehensive decision-making of transmission network planning based on entropy TOPSIS, Journal of North China Electric Power University, 4 (37): $24-28$.

Rezaei, S, Ghazanfari, S, Kazemi, Z. ve Karyani, AK. (2014). Access to healthcare facilities: case study of Kermanshah province, Journal of Kermanshah University Medical Science, 18: 416-425.

Sun, L.Y., Miao, C.L. ve Yang, L. (2017). Ecological-economic efficiency evaluation of green technology innovation in strategic emerging industries based on entropy weighted TOPSIS method, Ecologic Indicators, 73:554-558.

Sun, R., Zhang, B. ve Liu, T. (2016). Ranking web service for high quality by applying improved entropy-topsis method" 2016 17th IEEE/ACIS International Conference on Software Engineering Artificial Intelligence Networking and Parallel/Distributed Computing (SNPD), May 2016, 249-254.

Syed H. Mandal U.K. Mondal S.P. (2016). Entropy based MCDM approach for Selection of material. National Level Conference on Engineering Problems and Application of mathematics, May. 2-7.

Tewari, P.C., Prakash, U. ve Khanduja, D. (2015). Ranking of sintered material for high loaded automobile application by applying Entropy-TOPSIS method, 4th International Conference on Materials Processing and Characterization, 2 (4-5): 2375-2379.

Triantaphyllou, E. (2000).Multi-criteria decision making methods: a comparative study, Promera Ed. Louisiana Usa: Springer-Science Business Media, 44.

Wang, L.J. ve Shao, X. L. (2010). Study on the safety production evaluation of the coal mine based on entropy-TOPSIS, Journal of Coal Science ve Engineering. 16 (3): 284-287.

Wang, Z. W. Tang, K. ve Yan, L. (2011). Comprehensive decision making of thermal power plant site based on entropy weight TOPSIS method, Safety and Environmental Engineering, 18 (5): 103-106.

Wang, Z.H., Zhan, W. ve Qiu, W.H. (2006). Application of an optimized entropy-TOPSIS multi-criteria decision making model to facilities management, International Journal of Plant Engineering Management, 11: 129-136.

Xuhong L., Yumin L., Zhenghua G. ve Wendong Y. (2004). Competitive situation analysis of regional logistics development based on AHP and entropy weight, Journal of Southeast University, 3: 398-401.

Xunping, L., Qiu, R. ve Yong, L. (2016). Evaluation of regional land use performance based on entropy TOPSIS model and diagnosis of its obstacle factors, Transactions of the Chinese Society of Agricultural Engineering, 32 (13): 243-253.

Yin, H., Shi, G. ve Li, B. (2011). Analysis and Evaluation of Developmental Vulnerability of Regional System Based on Entropy-TOPSIS Method, Operations Research and Management Science, 2: 136-144. 
Zavadskas E.K. Kaklauskas A. Turskis Z. Tamošaitienè J. (2008).Selection of the effective dwelling house walls by applying attributes values determined at intervals, Journal of Civil Engineering and Management, 14 (2): 85-93.

Zhang, H. Gu, C.L. Gu, L.W. ve Zhang, Y. (2011). The evaluation of tourism destination competitiveness by TOPSIS and information entropy-A case in the Yangtze River Delta of China, Tourism Management, 32 (2): 443-451.

Zhang, K. ve Zhou, D. (2008). Application of TOPSIS based on entropy and GD-AHP in evaluating sequence of air target threat, Journal of System Simulation, 20: 1661-1664.

Zhang, L. C. Zhu, F. Feng, T. ve Pingli, T. A. (2013). Evaluation and correlation analysis of land use performance based on entropy-weight TOPSIS method, Transactions of the Chinese Society of Agricultural Engineering, 29 (5): 217-227.

Zhang, Y. ve Luo, F. (2014), Industrial cluster competitiveness evaluation model research based on entropy weight TOPSIS method, Applied Mechanics and Materials, 584: 2676-2680.

Zhao J., Wang, T. ve Niu, D. (2004). Improved entropy TOPSIS of knight service evaluation in electric power marketing, Journal of North China Electric Power University, 31 (3): 68-71.

Zhao, H. ve Guo S. (2014). Selecting green supplier of thermal power equipment by using a hybrid MCDM method for sustainability, Sustainability, 6 (1): 217-235. 